Article

\title{
Aging Behavior of Aluminum Alloy 6082 Subjected to Friction Stir Processing
}

\author{
Khaled Al-Fadhalah * and Fahad Asi \\ Department of Mechanical Engineering, College of Engineering and Petroleum, Kuwait University, \\ P.O. Box 5969, Safat 13060, Kuwait; f.alasieng@gmail.com \\ * Correspondence: khaled.alfadhalah@ku.edu.kw
}

Received: 27 July 2018; Accepted: 16 August 2018; Published: 22 August 2018

\begin{abstract}
The present work examined the effect of artificial aging on the microstructure, texture, and hardness homogeneity in aluminum alloy AA6082 subjected to friction stir processing (FSP). Aging was applied to FSP samples at three different temperatures $\left(150^{\circ} \mathrm{C}, 175^{\circ} \mathrm{C}\right.$, and $\left.200{ }^{\circ} \mathrm{C}\right)$ for a period of $1 \mathrm{~h}, 6 \mathrm{~h}$, and $12 \mathrm{~h}$. Microstructure analysis using optical Microscopy (OM) and Electron Back-Scattered Diffraction (EBSD) indicated that FSP produced fine equiaxed grains, with an average grain size of $6.5 \mu \mathrm{m}$, in the stir zone (SZ) due to dynamic recrystallization. Aging was shown to result in additional grain refinement in the SZ due to the occurrence of recovery and recrystallization with either increasing aging temperature and/or aging time. An optimum average grain size of 3-4 $\mu \mathrm{m}$ was obtained in the SZ by applying aging at $175^{\circ} \mathrm{C}$. This was accompanied by an increase in the fraction of high-angle grain boundaries. FSP provided a simple shear texture with a major component of $B$ fiber. Increasing aging temperature and/or time resulted in the formation of recrystallization texture of a Cube orientation. In addition, Vickers microhardness was evaluated for the FSP sample, indicating a softening in the $\mathrm{SZ}$ due to the dissolution of the hardening precipitates. Compared to other aging temperatures, aging at $175{ }^{\circ} \mathrm{C}$ resulted in maximum hardness recovery $(90 \mathrm{Hv})$ to the initial value of base metal $(92.5 \mathrm{Hv})$. The hardness recovery is most likely attributed to the uniform distribution of fine hardening precipitates in the SZ when increasing the aging time to $12 \mathrm{~h}$.
\end{abstract}

Keywords: aging; friction stir processing; aluminum alloys; microstructure; texture; hardness

\section{Introduction}

Friction stir processing (FSP) has been used in the last two decades as an effective surface modification method for grain refinement in metals, particularly for aluminum alloys [1,2]. FSP was originally developed from the principle of friction stir welding (FSW), which has been utilized as a solid state joining technique [3]. The heat input caused by the friction between the FSP tool shoulder and the surface of the material, combined with the stirring action of the tool pin, results in grain refinement in the stir zone (SZ) due to the intensive plastic deformation. The SZ is commonly characterized by a fine and equiaxed grain structure with predominant high-angle grain boundaries (HAGBs), which is generally attributed to dynamic recrystallization and the break-up of constituent particles [2]. Next to the SZ, a narrow transition region known as the thermo-mechanically affected zone (TMAZ) is formed, followed by the heat affected zone (HAZ), and finally the unaffected base metal (BM). The grain refinement by FSP has been shown to enhance several properties, including strength, ductility, toughness, and corrosion resistance [4].

Several works have examined the effect of microstructural refinement by FSP/FSW on 6000 series aluminum alloys [5-12]. These heat-treatable series have a good weight-to-strength ratio, combined with excellent corrosion resistance and ease of formability [13]. They are heavily utilized in architecture and structural applications. The 6000 series consists of two major alloying elements: silicon (Si) 
and magnesium $(\mathrm{Mg})$. Both elements are important for precipitation hardening, and they are typically added in the proportions required for the formation of hardening precipitates of magnesium silicide $\left(\mathrm{Mg}_{2} \mathrm{Si}\right)$, thus rendering them heat treatable, typically by solutionizing and artificial aging. The hardening precipitates of $\mathrm{Mg}_{2} \mathrm{Si}$ do not only form at grain boundaries during aging, but they are expected to be randomly distributed on lattice vacancies throughout the grains. Moreover, for the 6000 series aluminum alloy, a significant increase in strength is achieved by precipitating the metastable precursors to the equilibrium $\beta\left(\mathrm{Mg}_{2} \mathrm{Si}\right)$ phase, such as $\beta$ " precipitates. The use of FSW /FSP on 6000 series aluminum alloys, originally strengthened by artificial aging, typically results in large frictional heat and intensive plastic deformation that cause dissolution and/or coarsening of the hardening precipitates in the SZ. Sauvage et al. [8] conducted FSW on Al-Mg-Si alloys and indicated that an ultra-fine grain structure is difficult to achieve in the weld/stir zone due to the instability of $\beta$ " precipitates. Less pinning effect was exerted by the coarse widely-spaced particles on the boundary mobility of recrystallized grains, resulting in a relatively large grain size. In addition, Woo et al. [11] examined FSP of AA6061 and reported that microstructural softening occurred in the SZ and TMAZ due to the dissolution of fine needle-shape precipitates $\beta^{\prime \prime}$ in the SZ and TMAZ.

An early study by Sato et al. [6] examined the formation of precipitates in FSW of the AA6063 alloy by artificial aging. Despite the formation of fine recrystallized grains, the dissolution and growth of precipitates were noticed in the weld zone after FSW. By applying aging, it was found that hardening precipitates reformed, leading to a full recovery of the microhardness. Cabibbo et al. [14] also examined the effect of post-weld heat treatment (PWHT) on FSW of AA6056 and reported a considerable increase in strength of the weld zone due to the formation of a high density of fine $\mathrm{Mg}_{2} \mathrm{Si}$ precipitates. In addition, El-Danaf and El-Rayes [15] examined the effect of PWHT on FSW of AA6082 at $175{ }^{\circ} \mathrm{C}$ for $5 \mathrm{~h}$ and $12 \mathrm{~h}$. Unlike the findings in Sato's work [6], PWHT led to a partial recovery in the hardness of the weld joint due to the re-formation of $\beta^{\prime \prime}$ precipitates. PWHT also caused no significant increase in the grain size, suggesting that the re-formation of $\beta^{\prime \prime}$ precipitates restricted any grain growth. Jamshidi Aval and Serajzadeh [16] also reported that post aging increased the hardness of the weld zone in AA6061 initially subjected to FSW.

The aforementioned studies indicated that post artificial aging is essential to acquiring a sufficient strength and hardness in the weld/stir zone of 6000 series aluminum alloys subjected to FSW/FSP, whenever a high loading condition is imposed. For such heat-treatable aluminum alloys, the temperature and period of the artificial aging play a significant role in the re-formation of $\beta^{\prime \prime}$ hardening precipitates in the SZ. Therefore, it is of importance to explore the effect of post artificial aging temperature and time on the microstructural development and mechanical properties in the SZ of 6000 series aluminum alloys subjected to FSP. In this paper, we highlight new findings for boosting grain refinement and enhancing hardness in the $\mathrm{SZ}$ of AA6082 subjected to FSP and a post heat treatment of artificial aging. Three different temperatures $\left(150{ }^{\circ} \mathrm{C}, 175{ }^{\circ} \mathrm{C}\right.$, and $\left.200{ }^{\circ} \mathrm{C}\right)$ were applied in the artificial aging and for a period of $1 \mathrm{~h}, 6 \mathrm{~h}$, and $12 \mathrm{~h}$. Optical Microscopy (OM), Electron Back-Scattered Diffraction (EBSD), and X-ray Diffraction (XRD) were utilized to analyze the evolution of the microstructure and texture in FSP and aged samples. The hardness in the SZ was evaluated using Vickers microhardness tests.

\section{Materials and Methods}

Aluminum alloy 6082 (Industrial Metal Center Company, Shuwaikh, Kuwait) plates were received in a hot rolled condition. The aluminum alloy has a chemical composition (in wt. \%) of $1.03 \mathrm{Si}, 0.76 \mathrm{Mg}$, $0.53 \mathrm{Mn}$, and $0.21 \mathrm{Fe}$, with minor amounts of $\mathrm{Ti}, \mathrm{Cu}, \mathrm{Ni}, \mathrm{Va}, \mathrm{Zn}$, and $\mathrm{Zr}$. The dimensions of the FSP plates were $150 \mathrm{~mm} \times 125 \mathrm{~mm} \times 13 \mathrm{~mm}$, as schematically illustrated in Figure 1a. FSP specimens were sectioned perpendicular to the rolling direction. The FSP tool material is made of heat-treated H13 steel; it has a shoulder of $25 \mathrm{~mm}$ in diameter and a $4 \mathrm{~mm}$ long pin with a $4 \mathrm{~mm}$ diameter. FSP of single pass was conducted using a vertical milling machine with a constant tool rotating rate of $1200 \mathrm{rpm}$ and travel speed of $150 \mathrm{~mm} / \mathrm{min}$. Figure 1a schematically illustrates FSP of AA6082 plates, where WD, 
$\mathrm{TD}$, and ND denote the processing, transverse, and normal directions of the plate, respectively. A post heat treatment of artificial aging was carried out on the FSP samples using three aging temperatures of $150{ }^{\circ} \mathrm{C}, 175^{\circ} \mathrm{C}$, and $200^{\circ} \mathrm{C}$. For each temperature, three aging periods of $1 \mathrm{~h}, 6 \mathrm{~h}$, and $12 \mathrm{~h}$ were utilized. All aging treatments were applied to the FSP samples using an electric muffle furnace (JSMF-270T, JSR, Gongju, Korea).

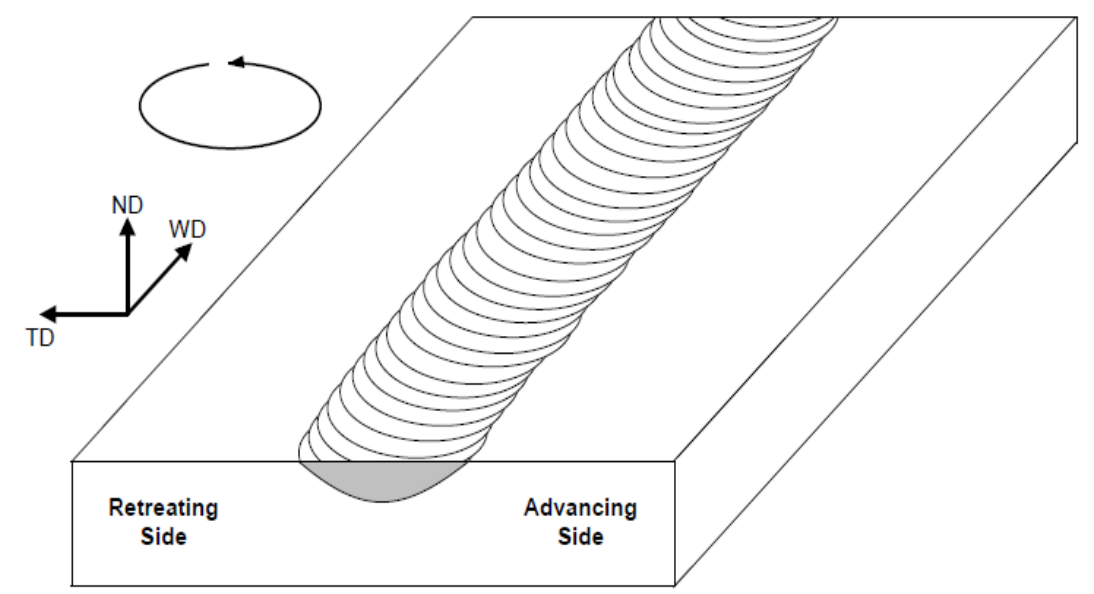

(a)

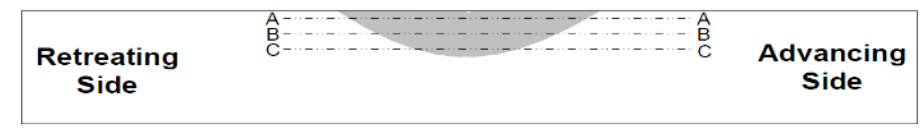

(b)

Figure 1. Schematic illustration of FSP: (a) geometry of the Al6063 plate with single pass showing the size of the processed zone and direction of tool rotation; $(\mathbf{b})$ cross-section of the plate showing lines of measurements for microhardness.

Metallographic samples were prepared for a microstructure evaluation of the processed area in FSP samples. The metallographic samples were cut from the cross-section of FSP plates (ND-TD plane) and then ground and polished using standard metallography techniques. Microstructure assessment of the processed area was first made using a (Stemi 2000c, ZEISS, Oberkochen, Germany). To do that, the samples were chemically etched at ambient temperature for about 6 min with an extended Flick's reagent consisting of 1.5 parts of $\mathrm{HCl}$, one part of $\mathrm{HF}$, and nine parts of distilled water. The microstructure was further analyzed using a metallurgical microscope (AxioImager A1M, ZEISS, Oberkochen, Germany). A microetchant of Weck's reagent was used to reveal grain boundaries, consisting of $100 \mathrm{~mL}$ distilled water, $4 \mathrm{gm}$ potassium permanganate, and $1 \mathrm{gm}$ sodium hydroxide. Particle size analysis for the intermetallic phases within the SZ was also conducted using ImageJ, an automated image analysis system [17]. Further assessment of the microstructure development in the SZ was carried out using the Electron Back-Scattered Diffraction (EBSD) technique. The EBSD measurements were conducted with an SEM (7001F-JSM, JEOL, Tokyo, Japan) equipped with an EBSD system (Aztec, Oxford, High Wycombe, UK). Samples were prepared by using an electro-polishing unit (LectroPol-5, Struers, Ballerup, Denmark) with an electrolyte containing $700 \mathrm{~mL}$ ethanol, $100 \mathrm{~mL}$ 2-butoxyethanol, $120 \mathrm{~mL}$ water, and $80 \mathrm{~mL}$ perchloric acid. EBSD measurements were made to assess the microstructure refinement and texture evolution in the processed area, evaluating grain size, grain boundary misorientation distribution, and pole figures. EBSD maps were acquired with an area of $225 \times 175 \mu \mathrm{m}^{2}$ with a step size of 0.1 to $0.3 \mu \mathrm{m}$. Depending on aging temperature and time, between nearly 750 and 1500 grains were analyzed for each EBSD map. This large number of grains allowed an adequate evaluation of microstructure and texture development. In addition, the critical misorientation angle used to discriminate grains from substructures was set to $10^{\circ}$. The average grain 
size was calculated according to ASTM: E112, using an average intercept method program available with the EBSD software. Further examination of the texture development in the SZ was also made by $X$-ray diffraction (XRD). The measurements were carried out by a diffractometer (model: Bruker, D8 Advance, Billerica, MA, USA) using $\mathrm{Cu} \mathrm{K} \alpha$ radiation at a scan rate of $0.02^{\circ}$ per second.

Additionally, hardness indentations were made using a Vickers microhardness tester (Micromet 4, Buehler, Lake Bluff, IL, USA). As schematically described in Figure 1b, the indentations were made horizontally on the cross-section of the processed plate at sections A-A, B-B, and C-C, i.e., 0.5, 1.5, and $2.5 \mathrm{~mm}$ from the processed surface, respectively. Indentations on each line were made in an increment of $0.5 \mathrm{~mm}$ and using a load of $200 \mathrm{gf}$ and dwell time of $15 \mathrm{~s}$.

\section{Results and Discussion}

\subsection{Microstructure}

\subsubsection{Friction Stir Processing}

Figure 2 demonstrates a low-magnification view of the transverse cross section, i.e., the ND-TD plane, of the FSP plate. Three distinct zones can be identified: SZ, TMAZ, and BM. No distinct HAZ was found for the FSP samples. In general, a basin-shape of the processed area was produced for all FSP samples. The microstructure in the SZ has been refined into very small grains. The TMAZ is very narrow, about 100-200 $\mu \mathrm{m}$, resulting in a sharp transition from a fine-grained SZ microstructure into a lamellar-type structure of flat elongated grains in the BM. The microstructure development in the BM is due to the use of hot rolling on the as-received AA6082 plates. In addition, no porosity or defects were generally detected in the processed area for all examined FSP samples.

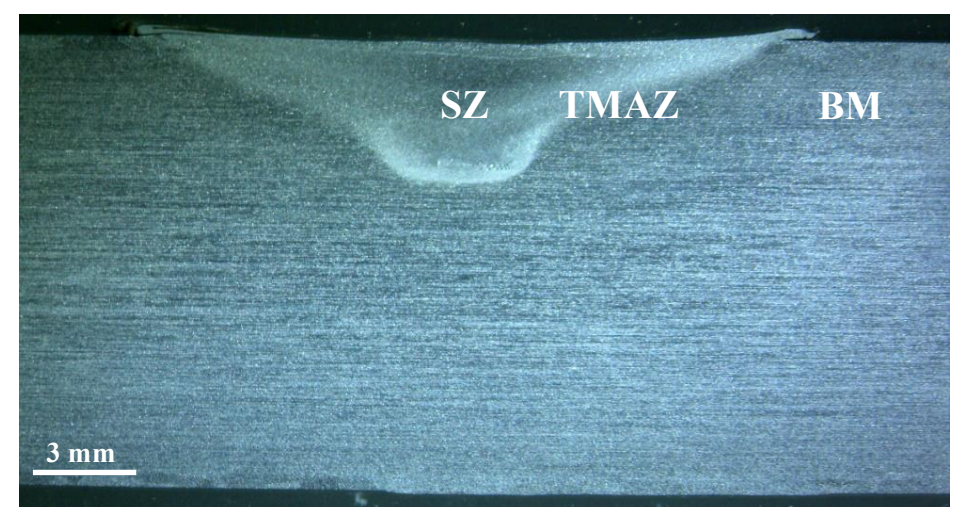

Figure 2. Low-magnification overview of the transversal cross-section of the AA6082 plate subjected to FSP.

Figure 3 shows optical micrographs illustrating the microstructure of each zone in the FSP plate. The structure of BM shows a typical deformed structure developed by rolling. The deformed structure is shown to be a lamellar type and aligned with the rolling direction. Most of the grains in the BM are small, with an average size of less than $10 \mu \mathrm{m}$. It is also evident that FSP produced an SZ that has relatively finer and equiaxed grains due to dynamic recrystallization. Such microstructure development is strongly related to the dual action of induced-friction heat and severe plastic deformation by stirring. In addition, the microstructure of the TMAZ indicated the severity of the deformation, as illustrated by the elongation of grains in the flow direction near to the TMAZ/BM interface without the occurrence of dynamic recrystallization. In addition, the microstructures in the three zones contain a large amount of intermetallic particles dispersed into the aluminum matrix. Based on particle size analysis, most of the intermetallic particles are in the range of 1-3 $\mu \mathrm{m}$, with minor differences in their distribution among the three regions. 


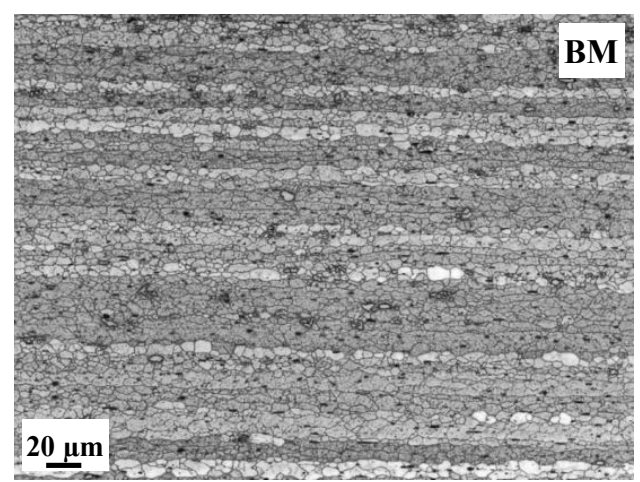

(a)

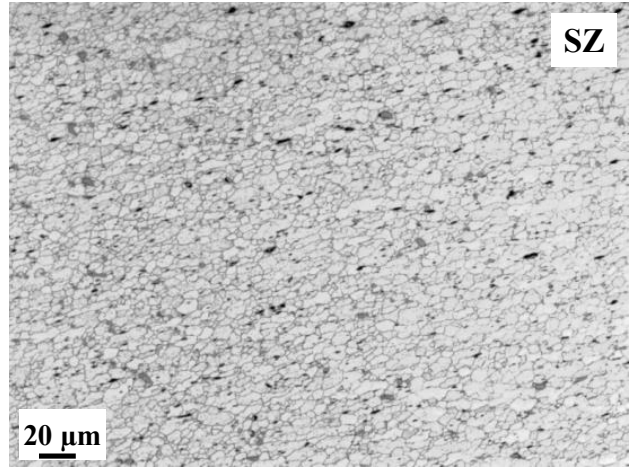

(b)

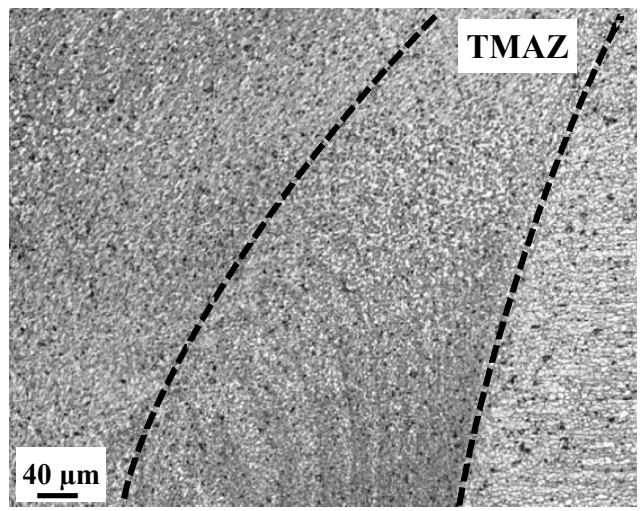

(c)

Figure 3. Optical micrograph images of the FSP AA6082 sample: (a) BM; (b) SZ and (c) TMAZ.

Furthermore, Figure 4 shows EBSD grain boundary reconstruction maps and corresponding Euler maps of the FSP sample. Low-angle grain boundaries (LAGBs) and high-angle grain boundaries (HAGBs) are shown as light grey and black lines, respectively. LAGBs present grain boundaries with a misorientation angle $\theta \leq 15^{\circ}$, while HAGBs describe those with a misorientation angle $\theta \geq 15^{\circ}$. Figure 4 a shows the microstructure of the BM, indicating a large formation of fine grains with HAGBs. The corresponding Euler map in Figure $4 \mathrm{~b}$ also shows the development of a lamellar structure. The microstructure of the SZ shown in Figure 4c indicates a relative reduction in the grain size due to the occurrence of dynamic recovery during FSP. The formation of recrystallized grains resulted in an increase in the fraction of HAGBs and the formation of grains of new orientations, as illustrated by the Euler map (Figure $4 \mathrm{~d})$. Yet, the SZ still contains a large fraction of LAGBs $(\sim 50 \%)$, which suggests that the microstructure had partly undergone dynamic recrystallization during FSP. This resulted in heterogeneous microstructural development in the SZ having primarily two microstructural constituents: small dynamically recrystallized grains that are dislocation-free, and larger recrystallized grains with a moderate dislocation density. The microstructure of TMAZ is shown in Figure 4e. 
As discussed, many of the grains are heavily distorted due to the stirring action near the undeformed BM. This led to the breakage of HAGBs and thus a reduction in the fraction of HAGBs. The Euler map in Figure $4 \mathrm{f}$ also shows that dynamic recovery was limited in TMAZ since the amount of heat is expected to be lower than that produced in the SZ. In addition, Table 1 summarizes EBSD statistics for the average grain size and grain boundary misorientation. The results show that SZ consists of a relatively smaller grain size $(6.5 \mu \mathrm{m})$, compared to the TMAZ $(7.2 \mu \mathrm{m})$ and BM $(8.2 \mu \mathrm{m})$. It is also shown that SZ has the maximum percentage of HAGBs (50.4\%) compared to TMAZ (26.8\%) and BM $(32.9 \%)$, confirming the occurrence of dynamic recrystallization. On the other hand, the reduction of HAGBs in TMAZ also suggests that the structure development in TMAZ was solely controlled by the severe plastic deformation and the occurrence of dynamic recrystallization was very limited. This resulted in an increase in the formation of LAGBs, mostly shown as subgrain walls, and the breakage of grain boundaries of high-angle misorientations.

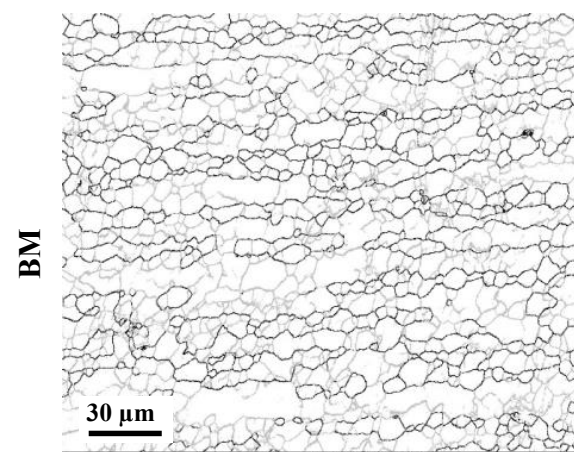

(a)

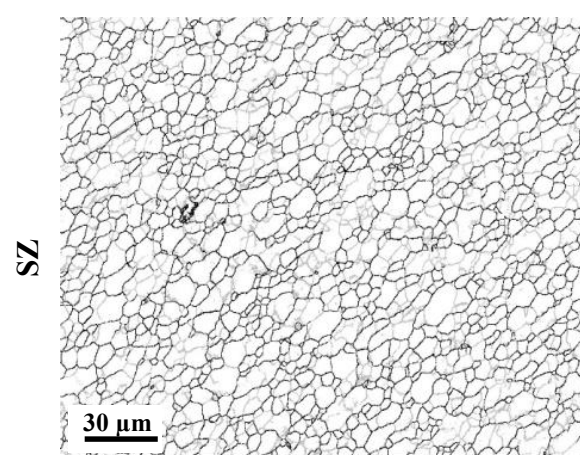

(c)

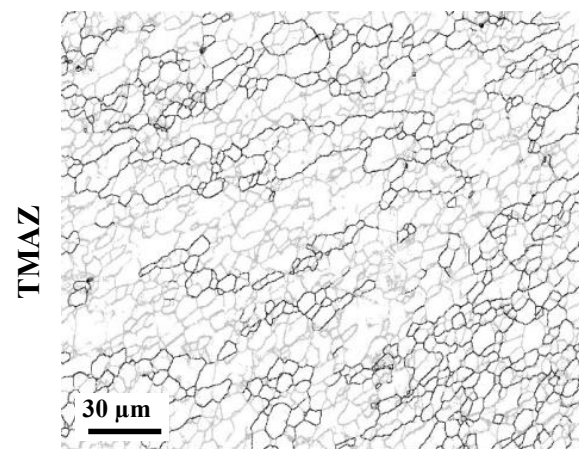

(e)

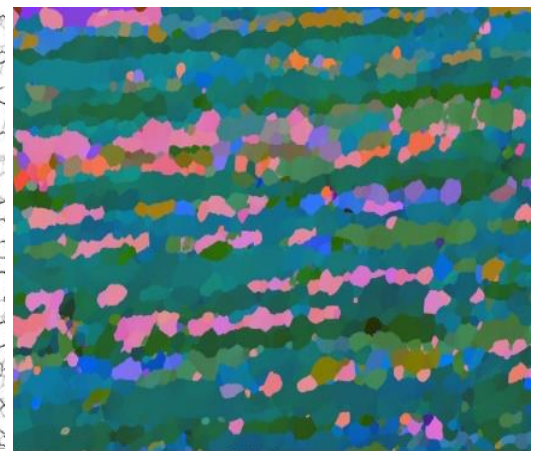

(b)

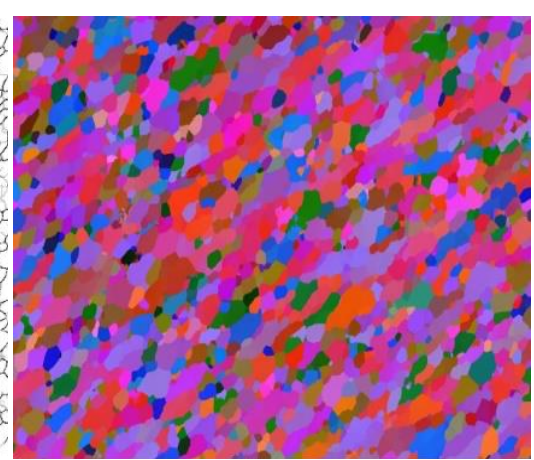

(d)

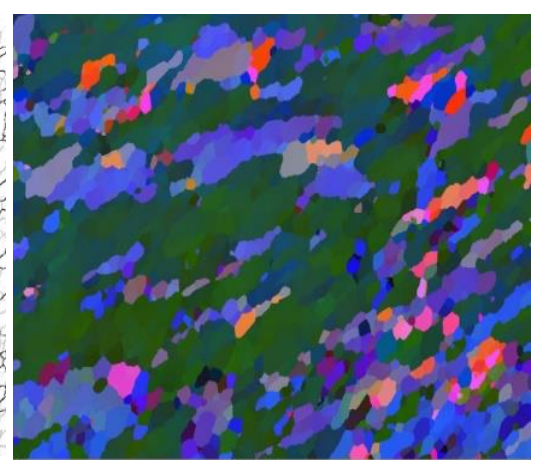

(f)

Figure 4. EBSD Grain boundary reconstruction maps and corresponding Euler maps for the FSP AA6082 sample: (a,b) BM; (c,d) SZ; (e,f) TMAZ. 
Table 1. Statsitics of grain size and grain boundary misoreietnation for FSP AA6082 sample.

\begin{tabular}{cccc}
\hline Zone & SZ & TMAZ & BM \\
\hline Grain size $(\mu \mathrm{m})$ & 6.5 & 7.2 & 8.2 \\
LAGBs $(\%)$ & 49.6 & 73.2 & 67.1 \\
HAGBs $(\%)$ & 50.4 & 26.8 & 32.9 \\
\hline
\end{tabular}

Moreover, the EBSD results demonstrate the formation of small equiaxed grains with HAGBs in SZ due to dynamic recrystallization during FSP. It is anticipated that limited growth of the newly formed grains will occur during post-dynamic recrystallization, i.e., metadynamic recrystallization. This is attributed to the presence of precipitates and intermetallic particles that can delay both static and dynamic recrystallization, including metadynamic recrystallization [18]. The development of different microstructure constituents in the SZ is expected to result in different static restoration behavior upon applying post heat treatment. Sakai et al. [19] have identified different restoration mechanisms during post annealing of hot-deformed metallic alloys. The small recrystallized nuclei, formed during hot deformation, may continue to grow during the early stages of post deformation annealing by the mechanism of metadynamic recrystallization. For the large recrystallized grains, the restoration process depends on the density of dislocation contained in the structure. If the dislocation density is low, below a critical density value required for recrystallization, then recovery occurs. For a higher dislocation density, the large grains may subsequently recrystallize statically.

In addition, the formation of recrystallized grains in SZ might also be affected by the presence of large second-phase particles. In such cases, recrystallization can be triggered by particle stimulated nucleation (PSN) for metallic alloys containing second-phase particles, such as in the case of AA6082 [20]. During plastic deformation, hard particles are expected to deform much less than the matrix phase. This typically leads to the development of strain gradient and lattice rotation around the particles, creating the so-called particle deformation zone (PDZ). In the case of the recrystallization of the deformed structure, the PDZ can act as a site for the nucleation of new grains via PSN. The size of particles for PSN is typically larger than $1 \mu \mathrm{m}$ [20]. This is required to form an appreciable PDZ around the particle during the deformation. However, PSN is mainly effective for low-temperature deformation and it becomes less viable, but possible, for hot deformation processes such as FSP. The current findings show no strong correlation between the presence of second-phase particles and the development of fine grains in SZ during dynamic recrystallization. Also, it should be noted that second phase particles can have a dual effect on recrystallization since they can promote and hinder recrystallization. In the case of closely-spaced and small particles, recrystallization can be retarded since the particles can prevent subgrain and grain boundary movement by Zener pinning [21].

\subsubsection{Artifical Aging}

The effect of artificial aging on the microstructural development in the SZ of FSP AA6082 samples was examined using EBSD. To do that, three aging temperatures of $150{ }^{\circ} \mathrm{C}, 175^{\circ} \mathrm{C}$, and $200{ }^{\circ} \mathrm{C}$ were used for an aging period of $1 \mathrm{~h}, 6 \mathrm{~h}$, and $12 \mathrm{~h}$. Figure 5 shows EBSD grain boundary construction and Euler maps of the SZ for FSP samples aged at $150^{\circ} \mathrm{C}$. Aging at $1 \mathrm{~h}$ produced no significant difference in the grain size compared to those produced by the FSP condition (Figure 5a). Also, the distribution of Euler orientations shown in Figure $5 b$ is similar to the FSP condition. However, there is an increase in the LAGBs compared to the FSP sample. This is mostly likely attributed to the presence of a large number of subgrains of LAGBs. The results also show the scattered formation of fine grains with a size of less than $1 \mu \mathrm{m}$. Most of the fine grains possess HAGBs. Moreover, grain growth in some regions is shown to occur when aging at $150{ }^{\circ} \mathrm{C}$ for $6 \mathrm{~h}$. This resulted in a reduction in the fraction of HAGBs, as demonstrated in Figure 5c,d. Subgrains of LAGBs are clearly shown to form within the large grains. The difference in microstructural development is strongly related to the variation in the dislocation density formed in the dynamically recrystallized structure during FSP. For grains with a 
low dislocation density, recovery is most likely to occur during post aging [19]. For grains with a high dislocation density, the grains may recrystallize statically after aging and subsequently grow. This indicates that both recovery and recrystallization had occurred during aging due to the microstructural inhomogeneity in the SZ induced by FSP. This is expected for recovery and recrystallization to occur since they have the same driving force, i.e., reduction in stored energy by a decrease in the amount of crystal defects. In addition, the results show the presence of small grains of a size of less than $1 \mu \mathrm{m}$, which are randomly nucleated in the large grains and at grain boundaries. When increasing the aging time to $12 \mathrm{~h}$, recrystallization was shown to occur, as presented by the formation of fine recrystallized grains of HAGBs. The size of the fine grains is in the range of $1-3 \mu \mathrm{m}$. The distribution of fine grains in the structure generally takes the form of a necklace, as demonstrated in Figure 5e,f. Also, some regions had not gone through recrystallization as they contain subgrains of LAGBs.

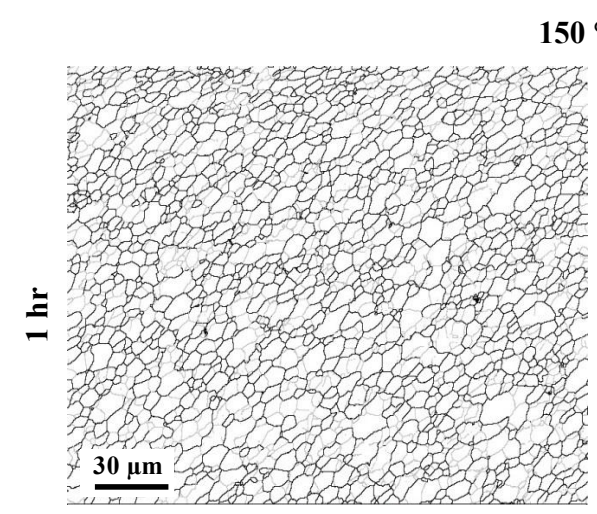

(a)

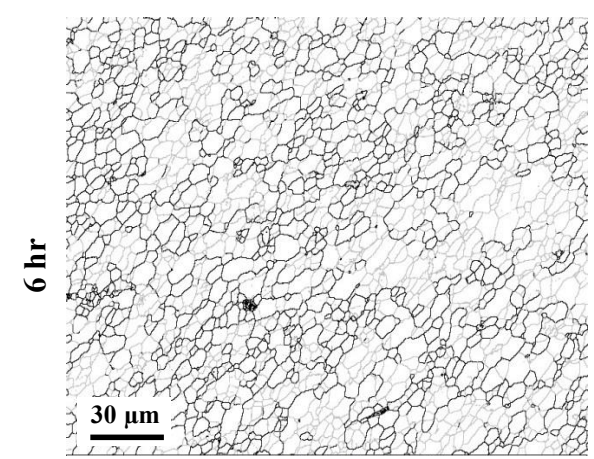

(c)

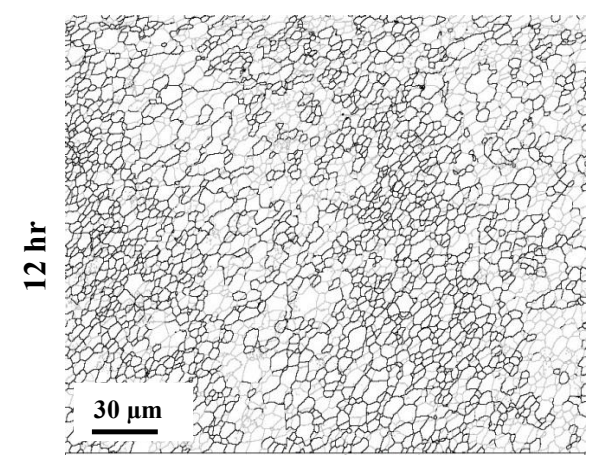

(e)

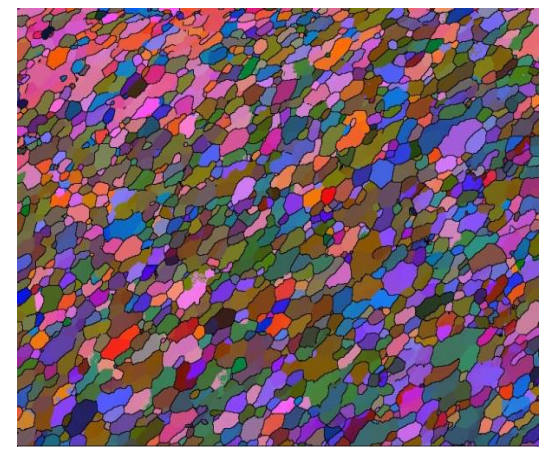

(b)

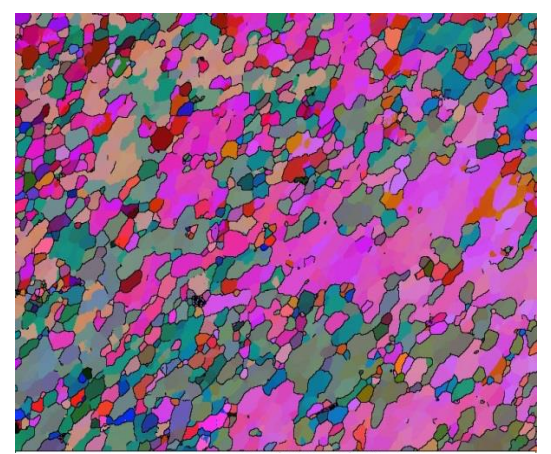

(d)

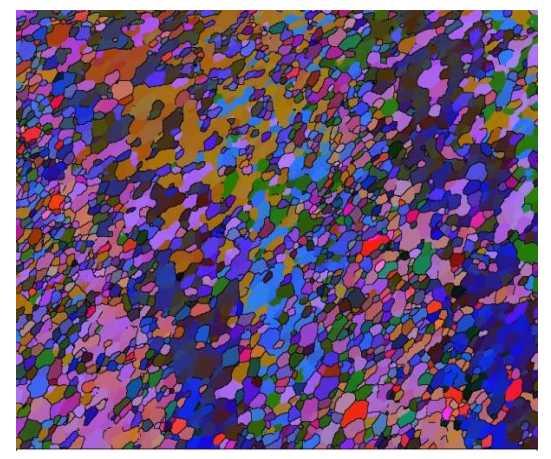

(f)

Figure 5. EBSD Grain boundary reconstruction maps and corresponding Euler maps of FSP AA6082 artificially aged at $150{ }^{\circ} \mathrm{C}$ for: (a,b) $1 \mathrm{~h}$; (c,d) $6 \mathrm{~h} ;(\mathbf{e}, \mathbf{f}) 12 \mathrm{~h}$.

Figure 6 presents the EBSD grain boundary construction and Euler maps of the SZ for artificially aged samples at $175^{\circ} \mathrm{C}$. Aging for $1 \mathrm{~h}$ is shown to result in recrystallization and the formation of fine 
grains. This is similar to microstructure development observed for the sample aged at $150{ }^{\circ} \mathrm{C}$ for $12 \mathrm{~h}$. Yet, the average grain size at $175^{\circ} \mathrm{C}$ for $1 \mathrm{~h}$ is smaller than that obtained by aging at $150{ }^{\circ} \mathrm{C}$ for $12 \mathrm{~h}$. This suggests that grain coarsening at $175^{\circ} \mathrm{C}$ was limited due to precipitate formation that resulted in hindering grain boundary migration by Zener pinning. It can also be noticed that some large grains were not fully recrystallized. These large grains contain a mixture of subgrains of LAGBs and newly recrystallized fine grains of HAGBs. Increasing the aging time to $6 \mathrm{~h}$ resulted in relatively coarser grains and a higher fraction of HAGBs. A further increase in aging time to $12 \mathrm{~h}$ led to insignificant change in the restoration process, as demonstrated by the recovery of a deformed structure possessing LAGBs and the recrystallization of fine grains of HAGBs.

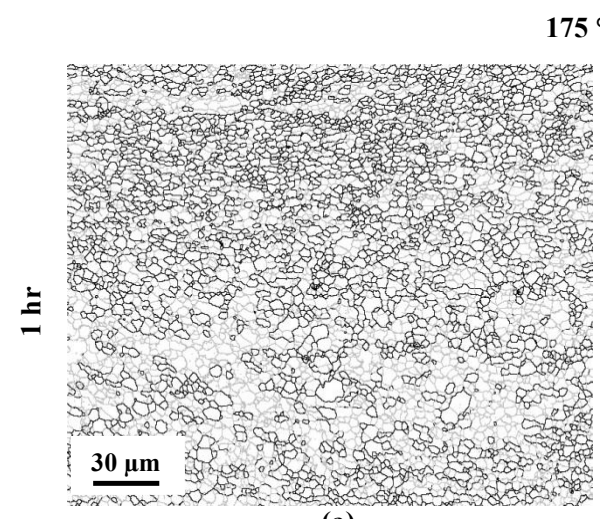

(a)

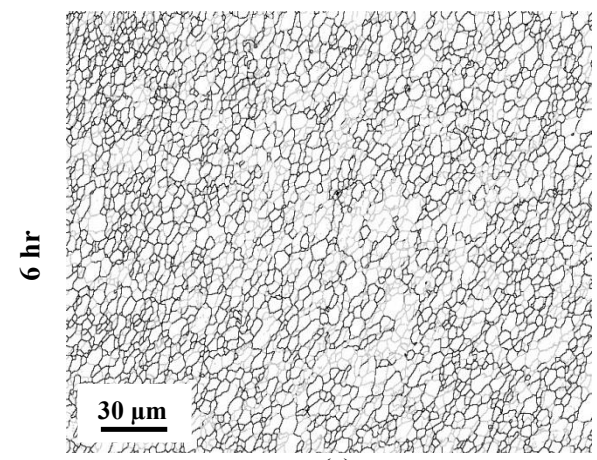

(c)

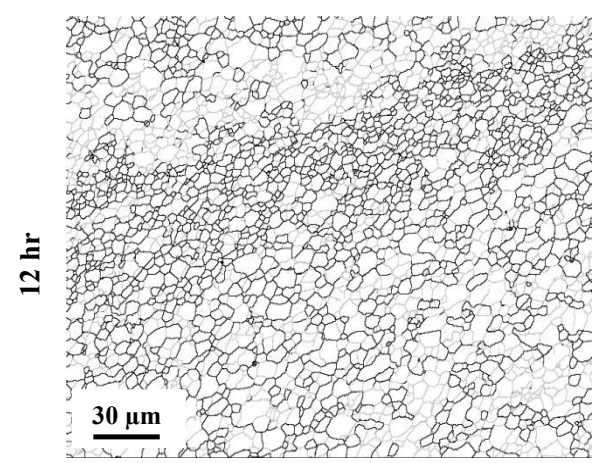

(e)

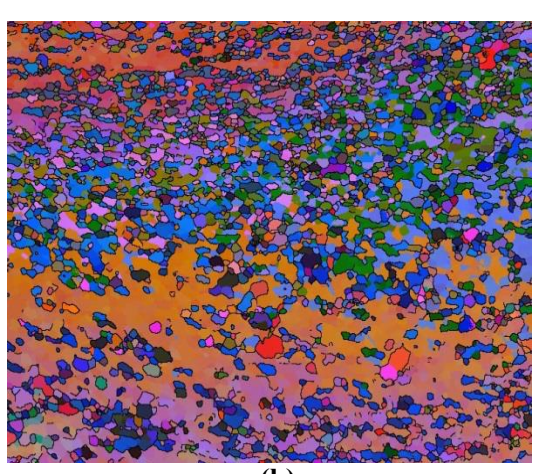

(b)

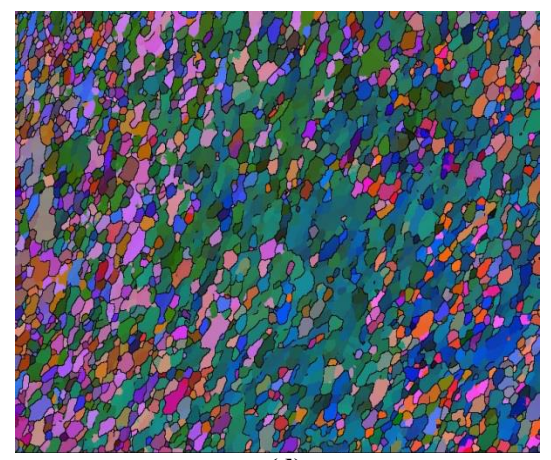

(d)

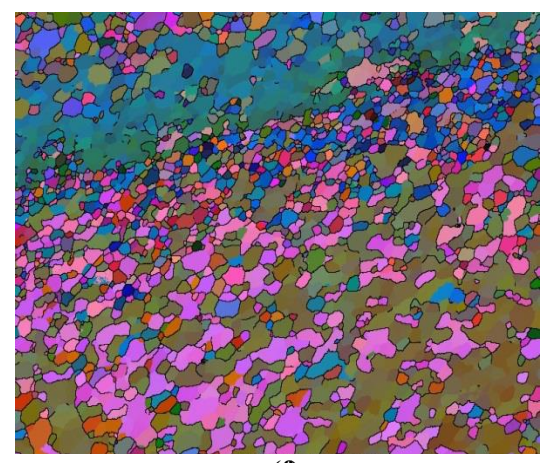

(f)

Figure 6. EBSD Grain boundary reconstruction maps and corresponding Euler maps of FSP AA6082 artificially aged at $175^{\circ} \mathrm{C}$ for: $(\mathbf{a}, \mathbf{b}), 1 \mathrm{~h} ;(\mathbf{c}, \mathbf{d}) 6 \mathrm{~h}$ and $(\mathbf{e}, \mathbf{f}) 12 \mathrm{~h}$.

Figure 7 shows the EBSD results of the SZ for artificially aged samples at $20{ }^{\circ} \mathrm{C}$. Aging for $1 \mathrm{~h}$ produced a microstructure that is composed of fine recrystallized grains with HAGBs and large grains with subgrains of LAGBs. Compared to $175{ }^{\circ} \mathrm{C}$ aging, the formation of fine recrystallized grains is shown to occur, but to a lesser extent. At $6 \mathrm{~h}$, the size of the recrystallized grains becomes coarser. 
Many of the LAGBs that belong to subgrains changed into HAGBs, suggesting the formation of new recrystallized grains. Increasing the aging time to $12 \mathrm{~h}$ only caused limited grain coarsening of the recrystallized grains. Otherwise, the microstructure looks similar to that obtained by aging at $200{ }^{\circ} \mathrm{C}$ for $6 \mathrm{~h}$. The large difference in Euler orientations for samples aged for $6 \mathrm{~h}$ and $12 \mathrm{~h}$, presented in Figure $7 \mathrm{~d}, \mathrm{f}$, confirms the strong occurrence of recrystallization.

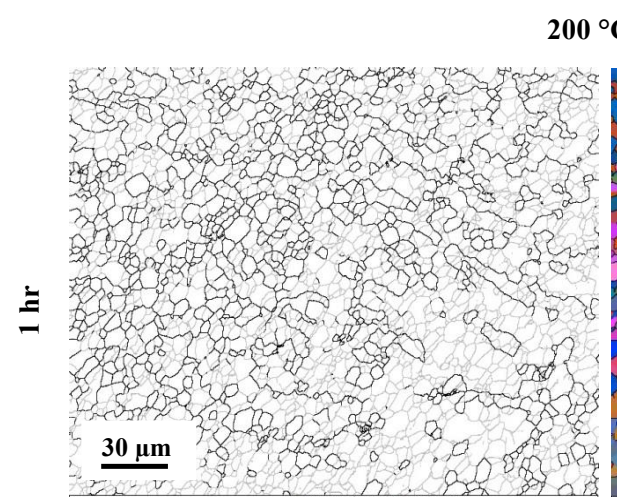

(a)

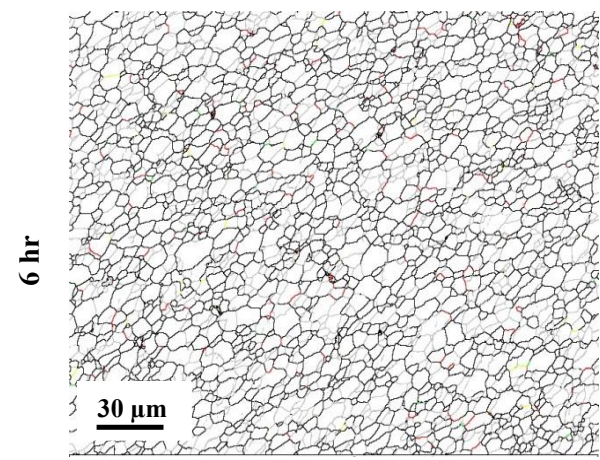

(c)

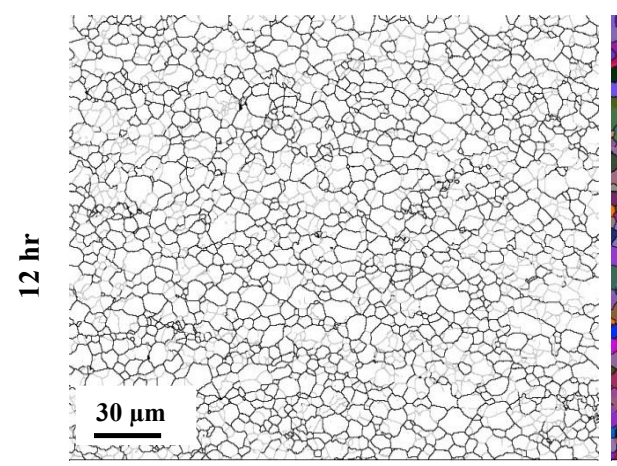

(e)

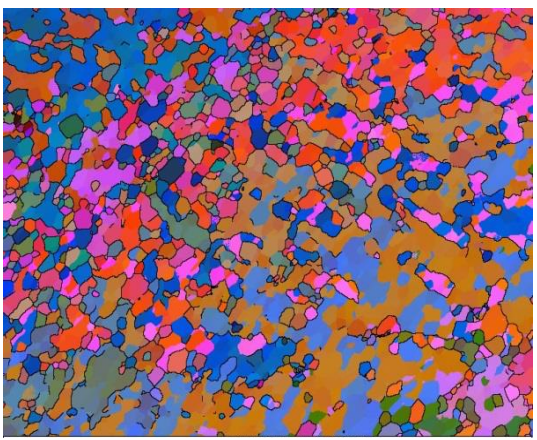

(b)

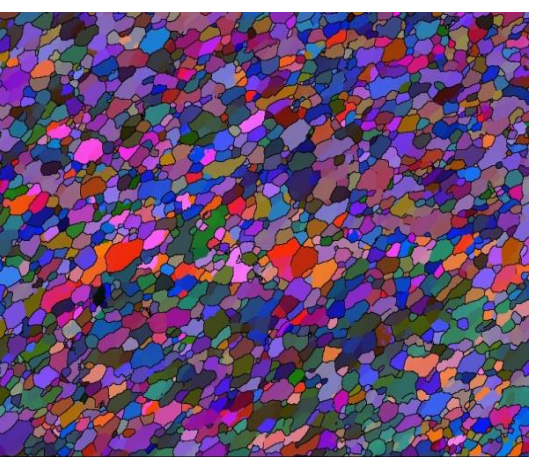

(d)

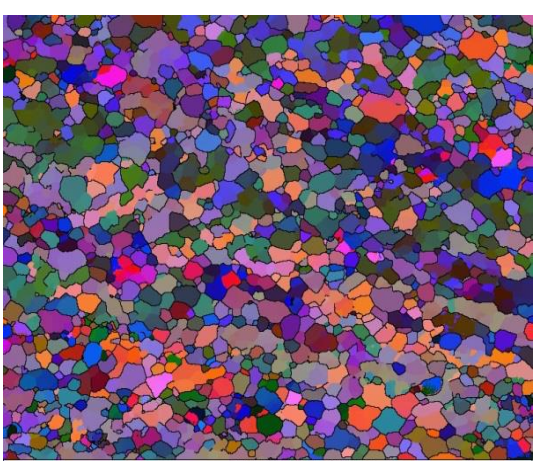

(f)

Figure 7. EBSD Grain boundary reconstruction maps and corresponding Euler maps of FSP AA6082 artificially aged at $200{ }^{\circ} \mathrm{C}$ for: $(\mathbf{a}, \mathbf{b}) 1 \mathrm{~h},(\mathbf{c}, \mathbf{d}) 6 \mathrm{~h} ;(\mathbf{e}, \mathbf{f}) 12 \mathrm{~h}$.

Table 2 summarizes the EBSD statistics for the average grain size, percentage of LAGBs, and HAGBs for each aging temperature and period. The results show that at $150{ }^{\circ} \mathrm{C}$, the grain size reduces significantly from $5.5 \mu \mathrm{m}$ at $1 \mathrm{~h}$ to $4.7 \mu \mathrm{m}$ at $6 \mathrm{~h}$ and to $4.1 \mu \mathrm{m}$ at $12 \mathrm{~h}$. As described earlier, the formation of fine recrystallized grains with increasing aging time strongly contributed to grain size reduction. Also, the occurrence of recrystallization led to an increase in the percentage of HAGBs for the sample aged for $12 \mathrm{~h}(55.5 \%)$ after it was at its minimum (46.6\%) at $6 \mathrm{~h}$. In the case of aging at $175^{\circ} \mathrm{C}$, recrystallization of fine grains occurred at a short aging period of $1 \mathrm{~h}$ that resulted in an average grain size of $3.55 \mu \mathrm{m}$. Limited grain growth occurred at $6 \mathrm{~h}$ and $12 \mathrm{~h}$, resulting in an increase in grain 
size to 4.5 and $4.6 \mu \mathrm{m}$, respectively. The increase in aging time also resulted in an increase in HAGBs, suggesting that further recrystallization occurred for a long period of aging at $175^{\circ} \mathrm{C}$. As previously described, aging at $200^{\circ} \mathrm{C}$ for $1 \mathrm{~h}$ provided less formation of fine grains of HAGBs. This resulted in a larger grain size $(\sim 6 \mu \mathrm{m})$ and lower fraction of HAGBs $(40 \%)$ compared to aging at $175^{\circ} \mathrm{C}$ for $1 \mathrm{~h}$. The structure for the sample aged at $200{ }^{\circ} \mathrm{C}$ for $6 \mathrm{~h}$ became fully recrystallized and thus resulted in equiaxed grains with an average grain size of $5.3 \mu \mathrm{m}$, providing the maximum percentage of HAGBs of $66.4 \%$. Additional aging to $12 \mathrm{~h}$ resulted in coarsening of the recrystallized grains. This led to an increase in the average grain size to $5.8 \mu \mathrm{m}$ and a reduction in the HAGBs percentage to $58 \%$.

Figure 8 presents grain size histograms for the aged samples. In the case of sample aged at $150{ }^{\circ} \mathrm{C}$ for $1 \mathrm{~h}$ (Figure $8 \mathrm{a}$ ), there is a relatively uniform grain size distribution from 1 to $10 \mu \mathrm{m}$, which looks similar to the distribution in the SZ for the FSP sample. Increasing the aging time to $6 \mathrm{~h}$ resulted in a higher frequency for grain size in the range of $1-4 \mu \mathrm{m}$, which suggests the growth of grain nuclei during aging and the development of subgrains with a higher misorientation angle (Figure 8b). Yet, some large grains are still present, with an average grain size of $15 \mu \mathrm{m}$. At $12 \mathrm{~h}$ of aging, recrystallization of fine grains occurred that resulted in an increase in the frequency of grains in the range of $1-4 \mu \mathrm{m}$ (Figure $8 \mathrm{c}$ ). Figure $8 \mathrm{~d}-\mathrm{f}$ shows the grain size distribution for samples aged at $175^{\circ} \mathrm{C}$. Stronger recrystallization occurred after $1 \mathrm{~h}$ of aging, as indicated by the high frequency for grain size in the range of $1-4 \mu \mathrm{m}$. With increasing aging time, coarsening of the recrystallized grains occurred, resulting in a lowering of the frequency for grains in the $1-4 \mu \mathrm{m}$ range. Aging at $200^{\circ} \mathrm{C}$ for $1 \mathrm{~h}$ led to a further reduction in the frequency of grains between 1 and $4 \mu \mathrm{m}$ (Figure 8g). Further aging resulted in grain coarsening and a more uniform distribution.

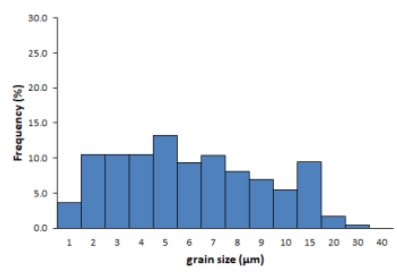

(a)

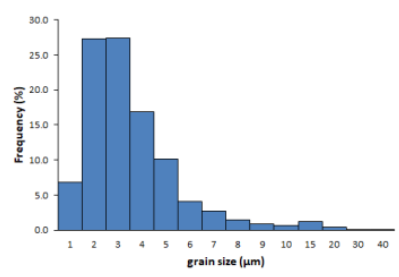

(d)

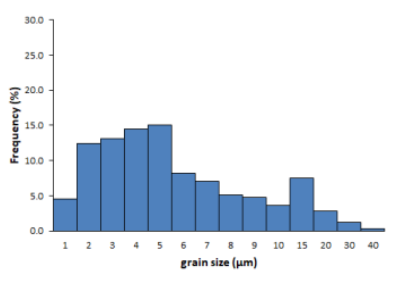

(g)

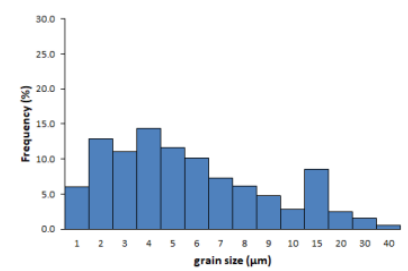

(b)

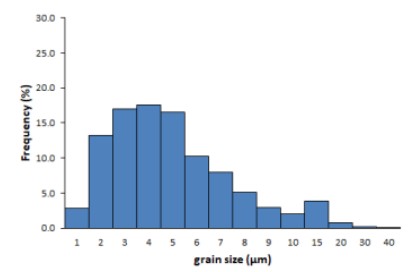

(e)

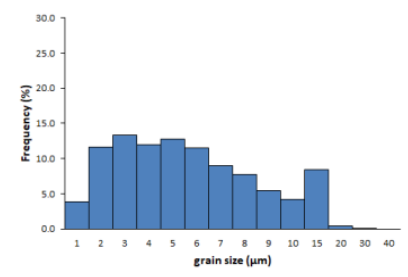

(h)

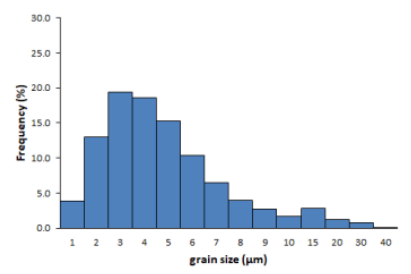

(c)

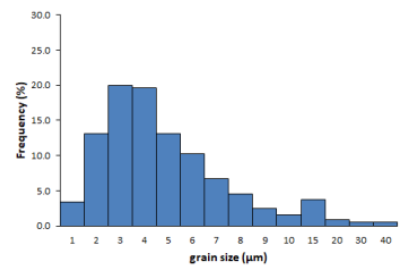

(f)

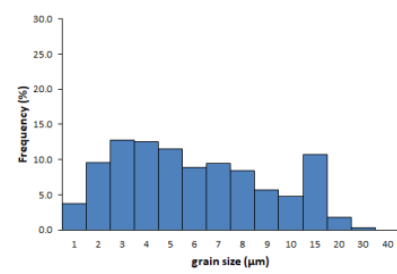

(i)

Figure 8. Grain size histograms for aged samples: (a) $150{ }^{\circ} \mathrm{C}$ for $1 \mathrm{~h}$; (b) $150{ }^{\circ} \mathrm{C}$ for $6 \mathrm{~h}$; (c) $150{ }^{\circ} \mathrm{C}$ for $12 \mathrm{~h}$; (d) $175^{\circ} \mathrm{C}$ for $1 \mathrm{~h}$; (e) $175^{\circ} \mathrm{C}$ for $6 \mathrm{~h}$; (f) $175^{\circ} \mathrm{C}$ for $12 \mathrm{~h}$; (g) $200{ }^{\circ} \mathrm{C}$ for $1 \mathrm{~h}$; (h) $200{ }^{\circ} \mathrm{C}$ for $6 \mathrm{~h}$ and (i) $200{ }^{\circ} \mathrm{C}$ for $12 \mathrm{~h}$. 
Table 2. Grain size and grain boundary statistics for FSP samples subjected to artificial aging.

\begin{tabular}{cccccccccc}
\hline $\begin{array}{c}\text { Aging } \\
\text { Temperature }\end{array}$ & \multicolumn{3}{c}{$\mathbf{1 5 0}^{\circ} \mathbf{C}$} & \multicolumn{3}{c}{$\mathbf{1 7 5}{ }^{\circ} \mathbf{C}$} & \multicolumn{3}{c}{$\mathbf{2 0 0}^{\circ} \mathbf{C}$} \\
\hline Aging Duration & $1 \mathrm{~h}$ & $6 \mathrm{~h}$ & $12 \mathrm{~h}$ & $1 \mathrm{~h}$ & $6 \mathrm{~h}$ & $12 \mathrm{~h}$ & $1 \mathrm{~h}$ & $6 \mathrm{~h}$ & $12 \mathrm{~h}$ \\
Grain size ( $\mu \mathrm{m})$ & 5.52 & 4.69 & 4.14 & 3.01 & 4.41 & 4.43 & 5.20 & 4.59 & 5.20 \\
LAGBs (\%) & 32.8 & 53.4 & 44.5 & 48.7 & 45.3 & 40.6 & 60.1 & 34.9 & 42.0 \\
HAGBs (\%) & 64.2 & 46.6 & 55.5 & 51.3 & 54.7 & 59.4 & 39.9 & 66.4 & 58.0 \\
\hline
\end{tabular}

\subsection{Texture}

The microstructure refinement by severe plastic deformation of FSP is greatly affected by the rotation of different parts of the original grains towards stable texture components. In the case of FSP, the stable texture components are strongly related to the predominant deformation mode of simple shear [22-24]. Shear textures are conventionally defined in terms of the crystallographic plane $\{h k l\}$ and direction $\langle u v w\rangle$, aligned with the shear plane and shear direction, respectively. In fcc metals, the shear textures are $\{h k l\}<1 \quad 1 \quad 0>$ fiber and $\left\{\begin{array}{llll}1 & 1 & 1\end{array}\right\}<u v w>$ fiber. The main ideal orientations along these fibers are illustrated in Figure 9 by the $\left(\begin{array}{lll}1 & 1 & 1\end{array}\right)$ pole figure projected on the SD-SPN plane, where $\mathrm{SD}$ is the shear direction and SPN is the shear plane normal [25].

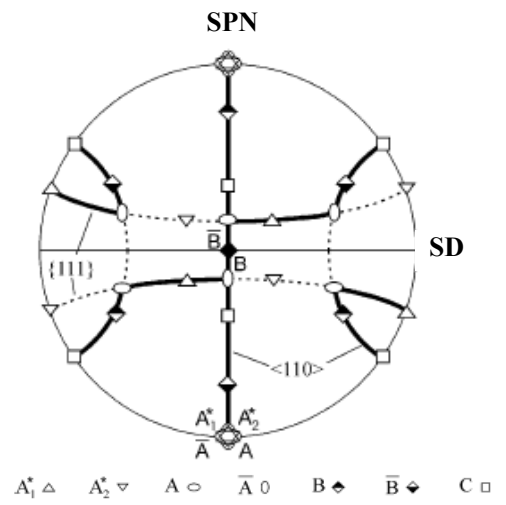

\begin{tabular}{|c|c|c|c|c|}
\hline \multirow[t]{2}{*}{ Notation } & \multirow[t]{2}{*}{$h k l$}$\langle u v w\rangle$ & \multicolumn{3}{|c|}{ Euler angles $\left({ }^{\circ}\right)^{a}$} \\
\hline & & $\varphi_{1}$ & $\phi$ & $\varphi_{2}$ \\
\hline \multirow[t]{2}{*}{$A_{1}^{*}$} & $\left(\begin{array}{lll}1 & 1 & 1\end{array}\right)\left[\begin{array}{ll}\overline{1} & \overline{1} \\
2\end{array}\right]$ & $35.26 / 215.26$ & 45 & $0 / 90$ \\
\hline & & 125.26 & 90 & 45 \\
\hline \multirow{2}{*}{$A_{2}^{*}$} & $\left(\begin{array}{lll}1 & 1 & 1\end{array}\right)\left[\begin{array}{lll}1 & 1 & \overline{2}\end{array}\right]$ & 144.74 & 45 & $0 / 90$ \\
\hline & & $54.74 / 234.74$ & 90 & 45 \\
\hline$A$ & $(1 \overline{1} 1)[110]$ & 0 & 35.26 & 45 \\
\hline $\bar{A}$ & $(\overline{1} 1 \overline{1})[\overline{1} \overline{1} 0]$ & 180 & 35.26 & 45 \\
\hline$B$ & $(\underline{1} \overline{1} 2)[110]$ & $0 / 120 / 240$ & 54.74 & 45 \\
\hline $\bar{B}$ & $(112)\left[\begin{array}{ll}1 & 10\end{array}\right]$ & $60 / 180$ & 54.74 & 45 \\
\hline \multirow[t]{2}{*}{ C } & $\{001\}\langle 110\rangle$ & $90 / 270$ & 45 & $0 / 90$ \\
\hline & & $0 / 180$ & 90 & 45 \\
\hline
\end{tabular}

Figure 9. Ideal orientations of FCC metals under simple shear in the $\left\{\begin{array}{llll}1 & 1 & 1\end{array}\right\}$ pole figure (Li et al. [25]). Note: SD is shear direction and SPN is shear plane normal.

Figure 10 presents the (111) pole figure of the experimental textures of the FSP samples for three regions: BM, SZ, and TMAZ. Figure 10a shows the texture of BM, demonstrating a typical rolling texture of strong copper orientation for fcc metals. The texture at the SZ presented in Figure $10 \mathrm{~b}$ mainly consists of $B$ fiber of the simple shear texture, i.e. $\{h k l\}\langle 110\rangle$, depicted by green. This suggests that the plastic flow at the center of the SZ strongly arises from the shear stress along the pin surface, and thus the shear plane and shear direction are roughly parallel to the pin surface and the rotating direction of the tool, respectively [26]. The shear texture of the $B$ fiber is also formed in TMAZ, as shown in Figure 10c, but clockwise rotated around the ND. Recrystallization texture of the Cube orientation, given in red, is also shown for TMAZ. Sato et al. [26] reported that regions relatively far from the SZ center do not display shear components similar to those detected at the center, but are rather affected by the shear stresses induced by the forward motion of the rotating pin and the rotation action of the tool shoulder. At these positions, the texture becomes a mixture of shear and recrystallization components.

Figure 11 represents the texture development in SZ for aged samples. The results show that the shear deformation texture of the $B$ fiber still existed, but rotated from the ideal shear axis and at a lesser intensity. This suggests that the grain formation of fine grains occurred in the SZ without large alteration of the SZ texture [27]. In addition, the aging treatments resulted in different recrystallization behaviors. In the case of $150{ }^{\circ} \mathrm{C}$, the recrystallization texture of the Cube orientation was strongly revealed when increasing the aging time to $12 \mathrm{~h}$. This is consistent with the formation 
of new recrystallized grains shown in Figure 5e. For samples aged at $175{ }^{\circ} \mathrm{C}$, the Cube orientation is clearly presented after $1 \mathrm{~h}$ of aging and became weaker with increasing aging time. For both aging temperatures, the shear texture of the $B$ fiber is partially preserved in the SZ, while the recrystallization texture of the Cube orientation is moderately formed. This suggests that the formation of hardening precipitates during aging was effective in hindering lattice rotation and limiting the grain growth of new crystallized grains. On the other hand, increasing the aging temperature to $200{ }^{\circ} \mathrm{C}$ resulted in an increase in the intensity of Cube orientation with aging time, while partially maintaining the shear texture. This indicates that recrystallization became strongly active by aging at $200{ }^{\circ} \mathrm{C}$, thus promoting the growth of new recrystallized grains of Cube orientation. Also, it can be inferred that the precipitation during aging at $200{ }^{\circ} \mathrm{C}$ is not sufficiently effective for hindering grain growth and lattice rotation, as demonstrated for samples aged at $150^{\circ} \mathrm{C}$ and $175^{\circ} \mathrm{C}$.

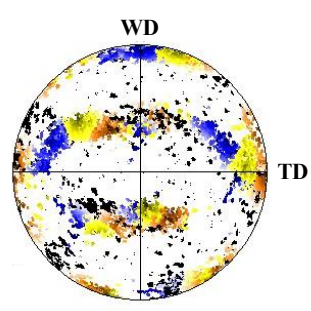

(a) BM

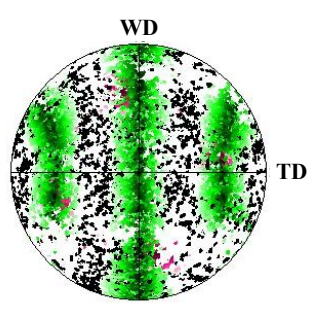

(b) $\mathrm{SZ}$

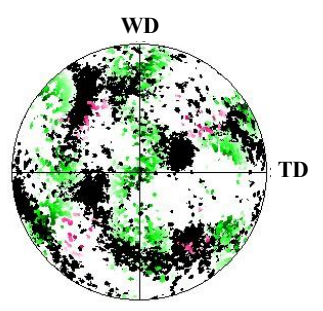

(c) TMAZ

Figure 10. $\left\{\begin{array}{lll}1 & 1 & 1\end{array}\right\}$ pole figures of FSP sample: (a) BM; (b) SZ, and (c) TMAZ. Texture components: brown (brass), blue (copper), yellow (S), green (B fiber), red (Cube).
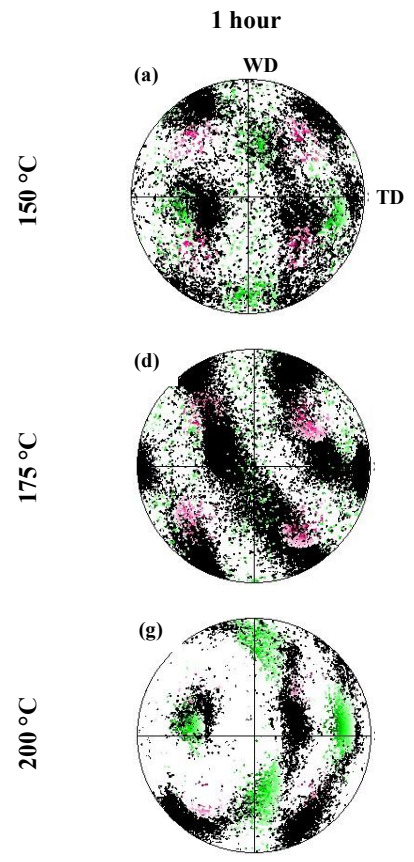
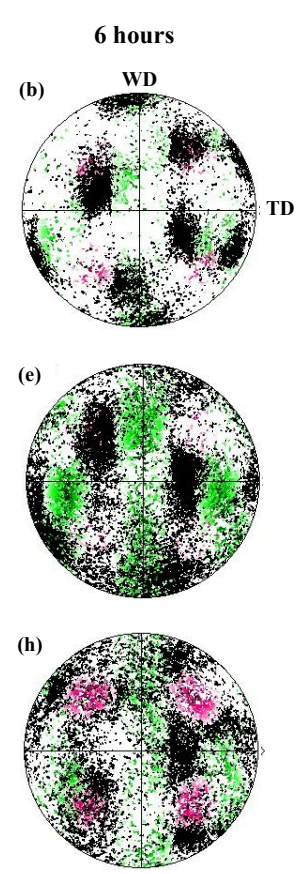
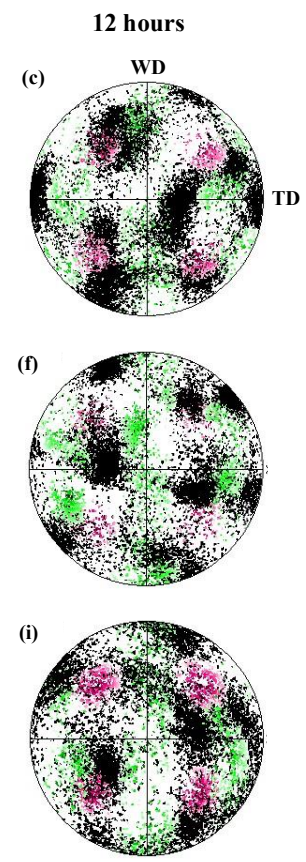

Figure 11. $\left\{\begin{array}{lll}1 & 1 & 1\end{array}\right\}$ pole figures of FSP samples aged at: $(\mathbf{a}-\mathbf{c}) 150{ }^{\circ} \mathrm{C} ;(\mathbf{d}-\mathbf{f}) 175^{\circ} \mathrm{C}$; and $(\mathbf{g}-\mathbf{i}) 200{ }^{\circ} \mathrm{C}$. Texture components: green ( $B$ fiber), red (Cube).

The effect of artificial aging on AA6082 samples processed by FSP has been further analyzed using XRD, as shown in Figure 12. In general, new intensities for the aluminum phase were shown to form after subjecting FSP samples to aging. Four distinct peak patterns of the $\mathrm{Al}$ matrix were clearly shown to form, corresponding to planes of (111), (200), (311) and (222), respectively. The only exception is for the sample aged at $150{ }^{\circ} \mathrm{C}$ for $1 \mathrm{~h}$, showing similar peak formation to that obtained 
in the FSP sample. It can also be generally seen that the (111) and (200) intensities become stronger with either increasing aging time or aging temperature, suggesting that the current aging treatments promoted recrystallization in the SZ with either increasing aging time or aging temperature. No specific intermetallic phases were identified and noted on their respective peaks. Generally, the absence of other peaks of alloying elements is mainly attributed to the limitation of X-ray in detecting phases with an amount of less than $2 \%$ volume fraction [28].

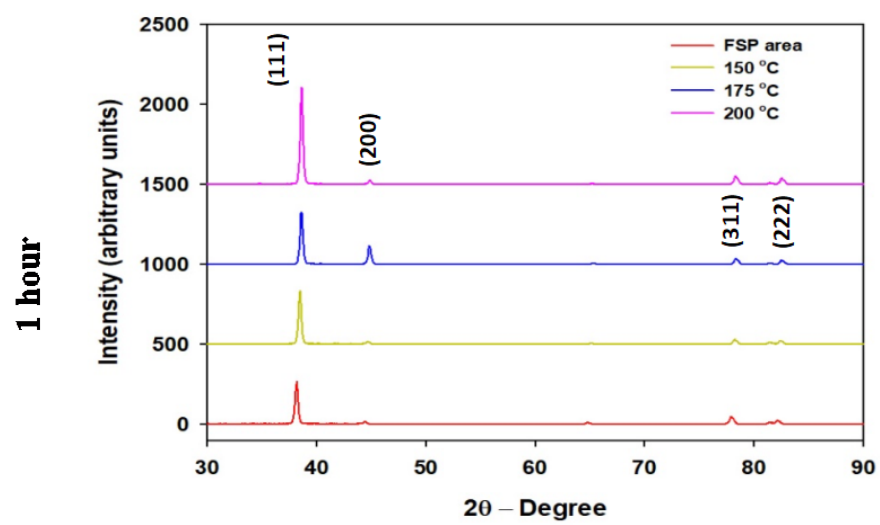

(a)

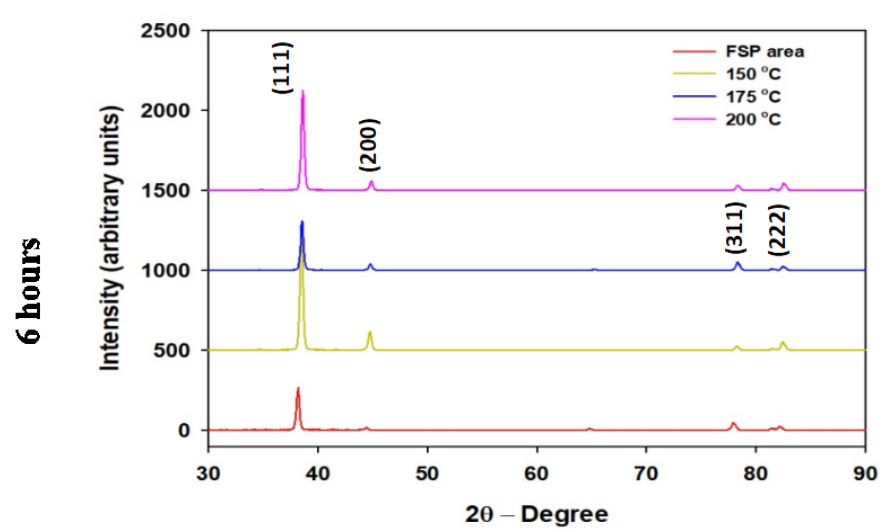

(b)

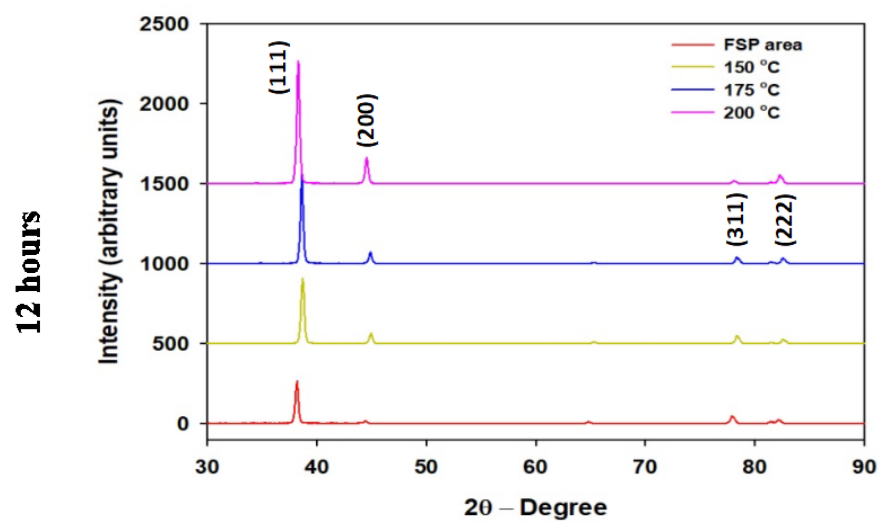

(c)

Figure 12. XRD patterns of AA6082 samples aged for: (a) $1 \mathrm{~h}$; (b) $6 \mathrm{~h}$ and (c) $12 \mathrm{~h}$. 


\subsection{Hardness}

The Vickers microhardness profiles of the AA6082 sample in the FSP condition are shown in Figure 13. The indentations were made at the SZ area at three depths from the processed surface $(0.5 \mathrm{~mm}, 1.5 \mathrm{~mm}$, and $2.5 \mathrm{~mm}$, respectively), and at the BM region. The microhardness of the BM was measured to be $92.5 \mathrm{Hv}$, and it is depicted as a horizontal line in the plot. FSP is shown to result in significant softening in the SZ, reducing the microhardness to $64 \mathrm{Hv}$ on average. The reduction in hardness in SZ is due to dynamic recrystallization facilitated by the combined effect of plastic deformation and heat induced by friction during FSP. The microhardness reduction extended over a wide distance of approximately $12 \mathrm{~mm}$ from the center of the SZ. The measurements at $0.5 \mathrm{~mm}$ from the processed surface are shown to provide the highest hardness, while the lowest hardness occurred at the furthest line from the processed surface $(2.5 \mathrm{~mm})$. This indicated that the fastest cooling occurred at the processed surface, resulting in a finer grain size and enhanced reformation of the hardening precipitates. Moreover, it can be noticed that there is a variation in hardness values in the SZ and TMAZ. Such variation is due to the difference in the amount of local heat in the processed material occurring during the thermal cycle, which can remarkably affect the dissolution of the hardening precipitates during heating and later the precipitates reformation process upon cooling [27]. Also, the variation in hardness can be related to the newly redistributed locations of second phase particles and precipitates, and to the fragmentation of the precipitates due to intense plastic deformation [29].

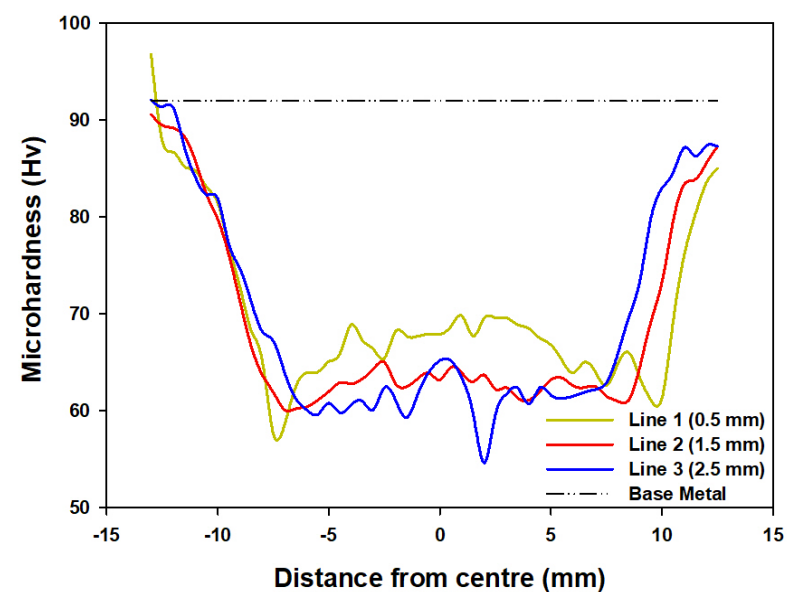

Figure 13. Vickers microhardness profile of the FSP AA6082 sample.

The effect of hardening precipitates formed by aging on the microhardness evolution of FSP was also examined as presented in Figure 14. For samples aged at $150{ }^{\circ} \mathrm{C}$ for $1 \mathrm{~h}$, the hardness at the SZ varied for each indentation line, with a hardness of $87 \mathrm{Hv}, 74 \mathrm{Hv}$, and $64 \mathrm{Hv}$ for lines 1, 2 and 3, respectively (Figure 14a). Additionally, the hardness values overall were higher for line 1, which is $0.5 \mathrm{~mm}$ from the processed surface, compared to the readings from lines 2 and 3 . Such differences indicate that precipitations occurred heterogeneously in the SZ, resulting in a stronger formation of hardening precipitates near to the top surface. The microhardness at TMAZ remains approximately unchanged, representing the lowest hardness values within the processed area. This is most likely attributed to the overaged microstructure resembled by the coarsening of the hardening precipitates in TMAZ that were previously subjected to heat during FSP [30]. A similar finding was also reported by Jamshidi Aval and Serajzadeh [16], who examined the post aging of AA6061 subjected to FSW and indicated low values of hardness in TMAZ/HAZ after natural aging for a long period of 250 days. Moreover, increasing the aging time to $6 \mathrm{~h}$ resulted in an increase in the hardness values at the SZ for all lines to 79-86 Hv, forming a similar hardness pattern to that shown in Figure $14 \mathrm{~b}$. At $12 \mathrm{~h}$ of aging, the microhardness showed an additional increase in hardness to about $90 \mathrm{Hv}$, while TMAZ remained at a low hardness of about $65 \mathrm{Hv}$. The SZ hardness values exceeded the hardness of the BM region 
subjected to a similar aging condition $(82 \mathrm{Hv})$. The drop of the BM hardness is mainly attributed to the prolonged aging period that resulted in coarsening of the hardening precipitates. Also, it has been noticed in Figure 14c that the prolonged aging of $12 \mathrm{~h}$ resulted in a sudden drop in the hardness in a few SZ points that are close to TMAZ. Such a drop indicates that the development of hardening precipitates occurred inhomogeneously, resulting in localized coarsening of the precipitates, and this contributed to the sudden drop in the hardness. Figure $14 \mathrm{~d}-\mathrm{f}$ presents the hardness profile for aged samples at $175^{\circ} \mathrm{C}$. For $1 \mathrm{~h}$ of aging, the hardness profile is similar to that obtained by $150{ }^{\circ} \mathrm{C}$ with a similar aging time. In particular, the hardness values in SZ range between 69 and $72 \mathrm{Hv}$, which are below the BM value of $88.7 \mathrm{Hv}$. Upon aging for $6 \mathrm{~h}$, the hardness changed significantly at the SZ, with a maximum value reaching $90 \mathrm{Hv}$. The hardness at the TMAZ also gradually increased to about $70 \mathrm{Hv}$. For $12 \mathrm{~h}$, it can be clearly seen that the hardness at the SZ has settled to the highest values between 90 and $93 \mathrm{Hv}$, which are above the BM hardness $(86 \mathrm{Hv})$, while the TMAZ hardness slightly increased to $73 \mathrm{Hv}$. Unlike aging at $150{ }^{\circ} \mathrm{C}$, a sudden drop in the SZ hardness was not observed in samples aged at $175^{\circ} \mathrm{C}$. This indicates the uniformity of hardness evolution within the SZ. Moreover, Figure $14 \mathrm{~g}-\mathrm{i}$ indicate that aging at $200{ }^{\circ} \mathrm{C}$ resulted in different hardness development when compared to that shown for aging treatments at $150^{\circ} \mathrm{C}$ and $175^{\circ} \mathrm{C}$. At $1 \mathrm{~h}$, the SZ hardness showed a remarkable increase to $78 \mathrm{Hv}$ compared to the sample in the FSP condition (64 Hv). The hardness in TMAZ is low, at about $60 \mathrm{Hv}$, while the BM showed a drop from $92.5 \mathrm{Hv}$ in the as-received condition (Figure 13) to about $84 \mathrm{Hv}$ (Figure 14g). After $6 \mathrm{~h}$ of aging, there is a noticeable reduction in the SZ hardness to approximately $68 \mathrm{Hv}$, while the BM hardness gradually dropped to about $75 \mathrm{Hv}$. Increasing aging time to $12 \mathrm{~h}$ resulted in an additional reduction in the hardness for both SZ and BM, as they became approximately identical $(70 \mathrm{Hv})$. Due to the use of a high aging temperature of $200{ }^{\circ} \mathrm{C}$, the hardness profiles suggest that the processed aluminum samples reached a stage of overaging, thereby decreasing the alloy strength to a minimum of $70 \mathrm{Hv}$ for both SZ and BM. It can also be noticed that a sudden drop in the hardness occurred in the SZ during $200{ }^{\circ} \mathrm{C}$ aging. This supports the previous findings presented in Figure 14c, which suggest that localized softening occurred due to different rates of precipitate formation and subsequent coarsening.

Table 3 summarizes the average hardness values in the SZ and BM for FSP and aged AA6082 samples. It is observed that the average hardness in the SZ increases with increasing aging time to about $90 \mathrm{Hv}$. In the case of aging at $150{ }^{\circ} \mathrm{C}$ and $175^{\circ} \mathrm{C}$, the hardness evolution of $\mathrm{BM}$ looks similar, but higher hardness values are obtained for $175^{\circ} \mathrm{C}$ at $12 \mathrm{~h}$. This generally indicates that aging at $175^{\circ} \mathrm{C}$ provided the optimum strengthening effect for both processed area and BM. In contrast, aging at $200{ }^{\circ} \mathrm{C}$ only resulted in a hardness increase for a short aging period of $1 \mathrm{~h}$. Increasing aging time resulted in a significant hardness reduction for both processed area and BM, suggesting the occurrence of overaging at this relatively high aging temperature.

Table 3. Average Vickers microhardness for FSP and artificially aged AA6082 samples.

\begin{tabular}{ccccccccccc}
\hline & \multirow{2}{*}{ FSP } & \multicolumn{3}{c}{$\mathbf{1 5 0}{ }^{\circ} \mathbf{C}$} & \multicolumn{3}{c}{$\mathbf{1 7 5}{ }^{\circ} \mathbf{C}$} & \multicolumn{3}{c}{$\mathbf{2 0 0}{ }^{\circ} \mathbf{C}$} \\
\cline { 3 - 11 } & & $\mathbf{1 ~ h}$ & $\mathbf{6} \mathbf{~ h}$ & $\mathbf{1 2} \mathbf{~ h}$ & $\mathbf{1} \mathbf{~ h}$ & $\mathbf{6} \mathbf{~ h}$ & $\mathbf{1 2} \mathbf{~ h}$ & $\mathbf{1} \mathbf{~ h}$ & $\mathbf{6} \mathbf{~ h}$ & $\mathbf{1 2} \mathbf{~ h}$ \\
\hline SZ (Hv) & 64.1 & 70.5 & 82.7 & 90.3 & 67.4 & 83.8 & 90.6 & 78.1 & 68.1 & 68.5 \\
BM (Hv) & 92.5 & 86.6 & 92.3 & 77.5 & 85.3 & 93.3 & 85.7 & 92.0 & 75.3 & 73.2 \\
\hline
\end{tabular}

The use of post weld heat treatment (PWHT) on FSP /FSW of 6000 series aluminum alloys has been previously investigated. Sato et al. [30] used PWHT for friction stir welded AA6063 at $175{ }^{\circ} \mathrm{C}$ for $5 \mathrm{~h}$ and $12 \mathrm{~h}$ and indicated a recovery of the hardness values in the SZ to that of BM; only partial recovery to hardness occurred in TMAZ. The increase in hardness was attributed to the reprecipitation of a large density of needle-shaped precipitates $\beta^{\prime \prime}$ in the SZ since there was an abundance of solute atoms of magnesium and silicon. In TMAZ, a high density of $\beta^{\prime}$ precipitates formed, consuming a large quantity of solutes, and thereby it was very difficult to form the needle-shaped precipitates $\beta^{\prime \prime}$. Also, 
Cabibbo et al. [14] have examined the PWHT of FSW of AA6056 and showed a considerable increase in strength of the joint due to the formation of a high density of fine $\mathrm{Mg}_{2} \mathrm{Si}$ precipitates. In addition, El-Danaf and El-Rayes [15] examined the effect of PWHT on FSW of AA6082 at $175^{\circ} \mathrm{C}$ for $5 \mathrm{~h}$ and $12 \mathrm{~h}$. Only partial recovery in the hardness of the joint occurred due to the re-precipitation of hard $\beta^{\prime \prime}$ particles during PWHT. There was no significant increase in the grains size after PWHT, suggesting that the re-precipitation of the $\beta$ " restricted any grain growth.

1 hour

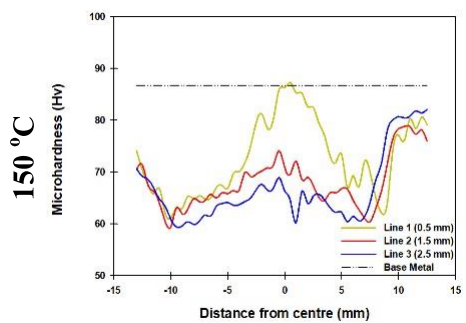

(a)

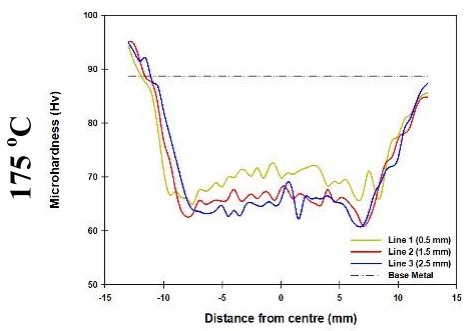

(d)

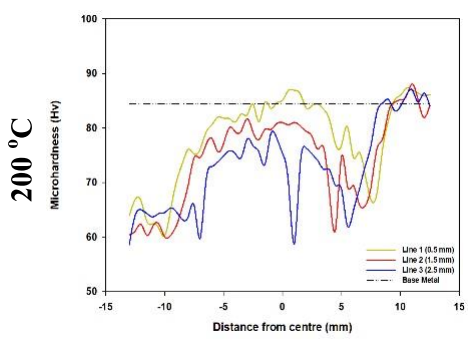

(g)
6 hours

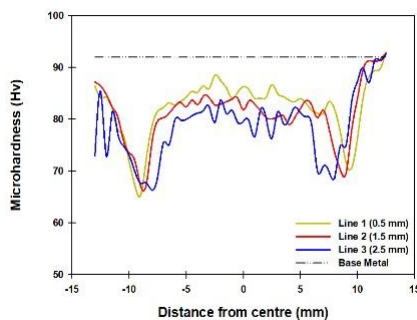

(b)

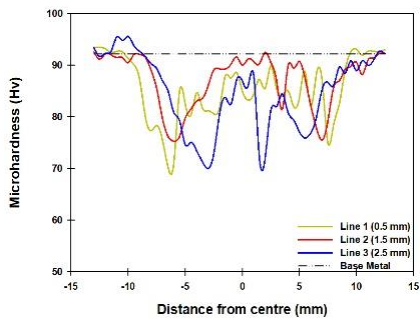

(e)

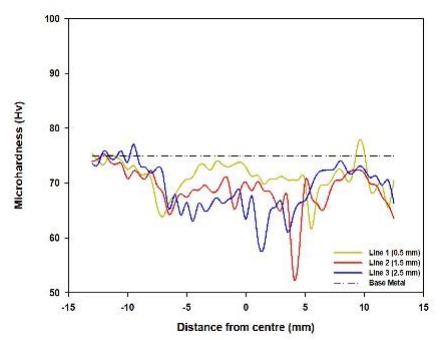

(h)
12 hours

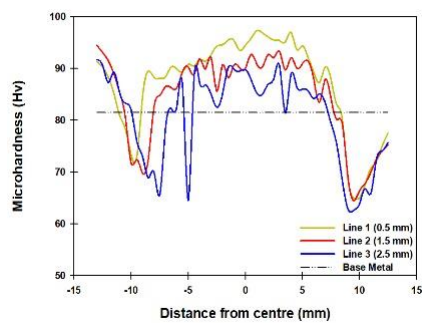

(c)

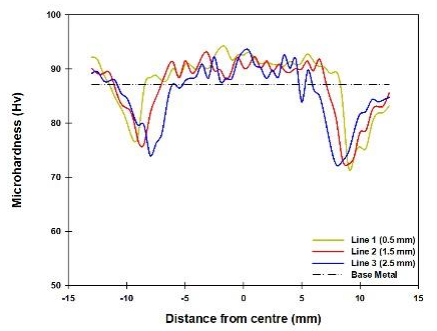

(f)

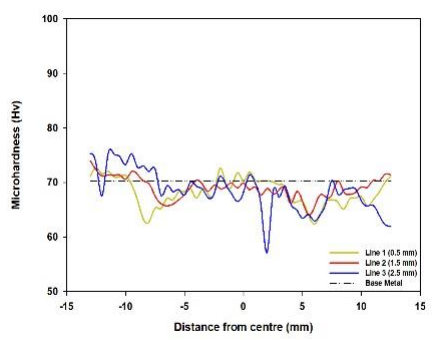

(i)

Figure 14. Vickers microhardness profiles of FSP samples aged at: $(\mathbf{a}-\mathbf{c}) 150{ }^{\circ} \mathrm{C} ;(\mathbf{d}-\mathbf{f}) 175^{\circ} \mathrm{C}$ and $(\mathbf{g}-\mathbf{i})$ $200{ }^{\circ} \mathrm{C}$.

The effect of aging on hardness development has also been examined in Al-Mg-Si alloys subjected to severe plastic deformation. Cerri and Leo [31] examined the artificial aging of AA6082 subjected to equal-channel angular pressing (ECAP) and reported that the use of high aging temperatures resulted in an increasing softening with time due to recovery and grain coarsening. At lower aging temperatures, the hardness remained almost constant owing to enhanced precipitation hardening over recovery and grain coarsening. Faré et al. [32] also studied the aging behavior of the 6082 alloy processed by ECAP and asymmetric rolling. It was indicated that aging at $180{ }^{\circ} \mathrm{C}$ led to a fast aging process, resulting in a continuous drop in hardness with increasing time due to the overwhelming effects of structure restoration. On the contrary, aging at $130^{\circ} \mathrm{C}$ provided a strong precipitate hardening effect in the ultrafine-grained material. In addition, other studies examined the effect of post annealing on precipitation and microstructural evolution in AA6082 subjected to severe rolling reductions [33,34]. It was reported that at a low annealing temperature of $150^{\circ} \mathrm{C}$, the formation of new subgrains occurred 
with an increase in the faction of HAGBs. At higher annealing temperatures, subgrain growth and recrystallization took place. Also, post annealing was shown to cause an increase in hardness due to the formation of second-phase precipitates, with a maximum hardness for samples treated at $160^{\circ} \mathrm{C}$ for $14 \mathrm{~h}$. Additional aging times resulted in a drop in the hardness due the post dynamic recovery and substructure coarsening. Furthermore, Chrominski [35] examined the aging behavior of AA6082 subjected to hydrostatic extrusion and pointed out that at short times of aging, precipitation hardening had a great influence on the increase of hardness rather than softening by dislocation annihilation or grain growth. After $14 \mathrm{~h}$ of aging, precipitation was shown to remain almost unchanged, but the hardness decreased due to grain growth and recovery processes.

\section{Conclusions}

Artificial aging was applied on aluminum alloy AA6082 initially subjected to FSP. The main objective was to evaluate the effect of artificial aging on the microstructure, texture, and mechanical properties of the processed area. This was achieved by using different aging temperatures and aging times $\left(150^{\circ} \mathrm{C}, 175^{\circ} \mathrm{C}\right.$, and $200^{\circ} \mathrm{C}$ and for $1 \mathrm{~h}, 6 \mathrm{~h}$ and $\left.12 \mathrm{~h}\right)$. The following conclusions can be drawn:

- $\quad$ FSP resulted in the formation of fine and equiaxed grains with predominant HAGBs in the SZ due to the occurrence of dynamic recrystallization. The FSP produced grain refinement in the SZ to $6.5 \mu \mathrm{m}$, as compared to the BM and TMAZ (8.2 and 7.2 $\mu \mathrm{m}$, respectively). A high fraction of HAGBs was recorded in the SZ, confirming the formation of recrystallized grains in the SZ.

- Long aging periods and/or high aging temperatures caused recovery, followed by recrystallization of fine grains in the range of $1-3 \mu \mathrm{m}$ within the SZ. Recovery occurred for short aging periods at $150{ }^{\circ} \mathrm{C}$, while the formation of fine recrystallized grains was shown after aging for $12 \mathrm{~h}$. Aging at $175^{\circ} \mathrm{C}$ resulted in the recrystallization of fine grains upon aging for $1 \mathrm{~h}$, while simultaneously increasing the fraction of HAGBs when increasing the aging period to 6 and $12 \mathrm{~h}$. In the case of $200{ }^{\circ} \mathrm{C}$ aging, a reduction of grain size initially occurred at $1 \mathrm{~h}$ of aging due to recrystallization. Longer aging times resulted in grain coarsening to $6 \mu \mathrm{m}$ and thereby lowering the fraction of HAGBs.

- $\quad$ FSP predominantly provided a simple shear texture in the SZ with a main component of $B$ fiber. Increasing aging temperature and/or aging time was shown to weaken the $B$ fiber and resulted in the formation of the recrystallization texture of Cube orientation. The formation of new fine grains and subsequent grain growth was particularly essential for strengthening the Cube orientation by the aging treatments used in the current study.

- Applying FSP resulted in significant softening in the SZ (64 Hv) compared to the BM (92.5 Hv). This is mostly attributed to the dissolution of the hardening precipitates $\beta^{\prime \prime}$ by the excessive heat of FSP. Aging at $175{ }^{\circ} \mathrm{C}$ for $12 \mathrm{~h}$ provided maximum recovery of the hardness in the SZ $(90 \mathrm{Hv})$, while maintaining the initial hardness value of the BM without a significant reduction $(86 \mathrm{Hv})$. Aging at $150{ }^{\circ} \mathrm{C}$ also enhanced the hardness of the SZ after $12 \mathrm{~h}(90 \mathrm{Hv})$, but it lowered the hardness of BM $(77 \mathrm{Hv})$. On the other hand, samples aged at $200{ }^{\circ} \mathrm{C}$ for $12 \mathrm{~h}$ showed a significant reduction in hardness for SZ $(68.5 \mathrm{Hv})$ and BM $(73 \mathrm{Hv})$, which implies the occurrence of overaging.

Author Contributions: K.A.-F. designed the experiments and significantly contributed to the writing of the paper; F.A. performed the experiments, analyzed the data, and helped in the preparation of the paper writing.

Funding: The authors gratefully appreciate the financial support from the College of Graduate Studies of Kuwait University.

Acknowledgments: The authors gratefully acknowledge the technical support provided by Kuwait University General Facility projects (GE 01/07 and GS 03/01) for sample preparation, optical microscopy, and EBSD and XRD measurements.

Conflicts of Interest: The authors declare no conflict of interest. 


\section{References}

1. Mishra, R.S.; Mahoney, M.W.; McFadden, S.X.; Mara, N.A.; Mukherjee, A.K. High strain rate superplasticity in a friction stir processed $7075 \mathrm{Al}$ alloy. Scripta Mater. 1999, 41, 163-168. [CrossRef]

2. Mishra, R.S.; Mahoney, M.W. Friction stir processing: A new grain refinement technique to achieve high strain rate superplasticity in commercial alloys. Mater. Sci. Forum 2001, 507, 357-359. [CrossRef]

3. Thomas, W.M.; Nicholas, E.D.; Needham, J.C.; Murch, M.G.; Temple-Smith, P.; Dawes, C.J. Friction Stir Butt Welding. International Patent Application No. PCT/GB92/02203; GB Patent Application No. 9125978.8; U.S. Patent Application No. 5,460,317, 6 December 1991.

4. Mishra, R.S.; Ma, Z.Y. Friction stir welding and processing. Mater. Sci. Eng. R 2005, 50, 1-78. [CrossRef]

5. Liu, G.; Murr, L.E.; Niou, C.S.; McClure, J.C.; Vega, F.R. Microstructural aspects of the friction-stir welding of 6061-T6 aluminum. Scripta Mater. 1997, 37, 355-361. [CrossRef]

6. Sato, Y.S.; Kokawa, H.; Enomoto, M.; Jogan, S. Microstructural evolution of 6063 aluminum during friction-stir welding. Metall. Mater. Trans. A 1999, 30, 2429-2437. [CrossRef]

7. Heinz, B.; Skrotzki, B. Characterization of a friction-stir-welded aluminum alloy 6013. Metall. Mater. Trans. B 2002, 33, 489-498. [CrossRef]

8. Sauvage, X.; Dédé, A.; Cabello Muñoz, A.; Huneau, B. Precipitate stability and recrystallisation in the weld nuggets of friction stir welded Al-Mg-Si and Al-Mg-Sc alloys. Mater. Sci. Eng. A 2008, 491, 364-371. [CrossRef]

9. Elangovan, K.; Balasubramanian, V. Influences of post-weld heat treatment on tensile properties of friction stir-welded AA6061 aluminum alloy joints. Mater. Charact. 2008, 59, 1168-1177. [CrossRef]

10. Elangovan, K.; Balasubramanian, V. Influences of tool pin profile and tool shoulder diameter on the formation of friction stir processing zone in AA6061 aluminum alloy. Mater. Des. 2008, 29, 362-373. [CrossRef]

11. Woo, W.; Choo, H.; Brown, D.W.; Feng, Z. Influence of the tool pin and shoulder on microstructure and natural aging kinetics in a friction-stir-processed 6061-T6 aluminum alloy. Metall. Mater. Trans. A 2007, 38, 69-76. [CrossRef]

12. El-Rayes, M.M.; El-Danaf, E.A. The influence of multi-pass friction stir processing on the microstructural and mechanical properties of aluminum alloy 6082. J. Mater. Process Technol. 2012, 212, 1157-1168. [CrossRef]

13. Imam, M.; Racherla, V.; Biswas, K. Effect of post-weld natural aging on mechanical and microstructural properties of friction stir welded 6063-T4 aluminium alloy. Mater. Des. 2014, 64, 675-686. [CrossRef]

14. Cabibbo, M.; McQueen, H.J.; Evangelista, E.; Spigarelli, S.; Di Paola, M.; Falchero, A. Microstructure and mechanical property studies of AA6056 friction stir welded plate. Mater. Sci. Eng. A 2007, 460, 86-94. [CrossRef]

15. El-Danaf, E.A.; El-Rayes, M.M. Microstructure and mechanical properties of friction stir welded 6082 AA in as welded and post weld heat treated conditions. Mater. Des. 2013, 46, 561-572. [CrossRef]

16. Jamshidi Aval, H.; Serajzadeh, S. A study on natural aging behavior and mechanical properties of friction stir-welded AA6061-T6 plates. Int. J. Adv. Manuf. Technol. 2014, 71, 933-941. [CrossRef]

17. Abramoff, M.D.; Magalhaes, P.J.; Ram, S.J. Image processing with ImageJ. Biophotonics Int. 2004, 11, $36-42$.

18. Schmitz, A.; Neutjens, J.; Herman, J.C.; Leroy, V. New thermomechanical hot rolling schedule for the processing of high strength fine grained multiphase steels. In Proceedings of the Mechanical Working and Steel Processing Conference Proceedings, Warrendale, PA, USA, 25-28 October 1998; pp. 295-310.

19. Sakai, T.; Ohashi, M.; Chiba, K.; Jonas, J.J. Recovery and recrystallization of polycrystalline nickel after hot working. Acta Metall. Mater. 1988, 36, 1781-1790. [CrossRef]

20. Humphreys, F.J.; Hatherly, M. Recrystallization and Related Annealing Phenomena, 2nd ed.; Pergamon Press: Oxford, UK, 2004.

21. Nes, E.; Ryum, N.; Hunderi, O. On the zener drag. Acta Metall. Mater. 1985, 33, 11-22. [CrossRef]

22. Fonda, R.W.; Bingert, J.F.; Colligan, K.J. Development of grain structure during friction stir welding. Scripta Mater. 2004, 51, 243-248. [CrossRef]

23. Prangnell, P.B.; Heason, C.P. Grain structure formation during friction stir welding observed by the 'stop action technique'. Acta Mater. 2005, 53, 3179-3192. [CrossRef]

24. Reynolds, A.P.; Hood, E.; Tang, W. Texture in friction stir welds of Timetal 21S. Scripta Mater. 2005, 52, 491-494. [CrossRef] 
25. Li, S.; Beyerlein, I.J.; Bourke, M.A. Texture formation during equal channel angular extrusion of fcc and bcc materials: comparison with simple shear. Mater. Sci. Eng. A 2005, 394, 66-77. [CrossRef]

26. Sato, Y.S.; Kokawa, H.; Ikeda, K.; Enomoto, M.; Hashimoto, T.; Jogan, S. Microtexture in the friction-stir weld of an aluminum alloy. Metall. Mater. Trans. A 2001, 32, 941-948. [CrossRef]

27. Al-Fadhalah, K.J.; Almazrouee, A.I.; Aloraier, A.S. Microstructure and mechanical properties of multi-pass friction stir processed aluminum alloy 6063. Mater. Des. 2014, 53, 550-560. [CrossRef]

28. Cullity, B.D. Elements of X-ray Diffraction, 3rd ed.; Prentice Hall: London, UK, 2001.

29. Dadbakhsh, S.; Taheri, A.K.; Smith, C.W. Strengthening study on $6082 \mathrm{Al}$ alloy after combination of aging treatment and ECAP process. Mater. Sci. Eng. A 2010, 527, 4758-4766. [CrossRef]

30. Sato, Y.S.; Urata, M.; Kokawa, H. Parameters controlling microstructure and hardness during friction-stir welding of precipitation-hardenable aluminum alloy 6063. Metall. Mater. Trans. A 2002, 33, 625-635. [CrossRef]

31. Cerri, E.; Leo, P. Influence of severe plastic deformation on aging of Al-Mg-Si alloys. Mater. Sci. Eng. A 2005, 410, 226-229. [CrossRef]

32. Faré, S.; Lecis, N.; Vedani, M. Aging behaviour of Al-Mg-Si Alloys subjected to severe plastic deformation by ECAP and cold asymmetric rolling. J. Metallurgy 2011, 2011, 959643. [CrossRef]

33. Kumar, V.; Kumar, D. Investigation of tensile behaviour of cryorolled and room temperature rolled $6082 \mathrm{Al}$ alloy. Mater. Sci. Eng. A 2017, 691, 211-217. [CrossRef]

34. Kumar, N.; Jayaganthan, R.; Brokmeier, H.G. Effect of deformation temperature on precipitation, microstructural evolution, mechanical and corrosion behavior of $6082 \mathrm{Al}$ alloy. Trans. Nonferrous Met. Soc. China 2017, 27, 475-492. [CrossRef]

35. Chrominski, W.; Lewandowska, M. Precipitation phenomena in ultrafine grained Al-Mg-Si alloy with heterogeneous microstructure. Acta Mater. 2016, 103, 547-557. [CrossRef]

(C) 2018 by the authors. Licensee MDPI, Basel, Switzerland. This article is an open access article distributed under the terms and conditions of the Creative Commons Attribution (CC BY) license (http://creativecommons.org/licenses/by/4.0/). 